Article

\title{
Chitosan-GPTMS-Silica Hybrid Mesoporous Aerogels for Bone Tissue Engineering
}

\author{
María V. Reyes-Peces ${ }^{1,2}$, A. Pérez-Moreno ${ }^{1,2} \mathbb{C}^{-}$, Deseada María de-los-Santos ${ }^{3}(\mathbb{D}$, \\ María del Mar Mesa-Díaz ${ }^{4,5}{ }^{(0)}$, Gonzalo Pinaglia-Tobaruela ${ }^{2,6}{ }^{\circledR}$, Jose Ignacio Vilches-Pérez ${ }^{2,6}$, \\ Rafael Fernández-Montesinos ${ }^{2,6}$, Mercedes Salido ${ }^{2,6}$, Nicolás de la Rosa-Fox ${ }^{1,5}$ and \\ Manuel Piñero 1,5,*(D) \\ 1 Department of Condensed Matter Physics 1, Faculty of Science, University of Cadiz, 11510 Cádiz, Spain; \\ Maria.reyes@uca.es (M.V.R.-P.); antoniopmoreno@gmail.com (A.P.-M.); nicolas.rosafox@uca.es (N.d.1.R.-F.) \\ 2 Instituto de Investigación e Innovación Biomédica de Cádiz (INIBICA), 11009 Cádiz, Spain; \\ gonzalo.pinaglia@uca.es (G.P.-T.); nachovilper@gmail.com (J.I.V.-P.); rafael.montesinos@uca.es (R.F.-M.); \\ mercedes.salido@uca.es (M.S.) \\ 3 Department of Physical Chemistry, Faculty of Science University of Cadiz, 11510 Cádiz, Spain; \\ desire.delossantos@uca.es \\ 4 Department of Chemical Engineering, Faculty of Science University of Cadiz, 11510 Cádiz, Spain; \\ mariadelmar.mesa@uca.es \\ 5 Instituto de Microscopía Electrónica y Materiales (IMEYMAT), University of Cadiz, 11510 Cádiz, Spain \\ 6 Department of Histology, SCIBM, Faculty of Medicine University of Cadiz, 11004 Cádiz, Spain \\ * Correspondence: manolo.piniero@gm.uca.es
}

Received: 30 October 2020; Accepted: 14 November 2020; Published: 17 November 2020

check for updates

\begin{abstract}
This study introduces a new synthesis route for obtaining homogeneous chitosan (CS)-silica hybrid aerogels with CS contents up to $10 \mathrm{wt} \%$, using 3-glycidoxypropyl trimethoxysilane (GPTMS) as coupling agent, for tissue engineering applications. Aerogels were obtained using the sol-gel process followed by $\mathrm{CO}_{2}$ supercritical drying, resulting in samples with bulk densities ranging from $0.17 \mathrm{~g} / \mathrm{cm}^{3}$ to $0.38 \mathrm{~g} / \mathrm{cm}^{3}$. The textural analysis by $\mathrm{N}_{2}$-physisorption revealed an interconnected mesopore network with decreasing specific surface areas $\left(1230-700 \mathrm{~m}^{2} / \mathrm{g}\right)$ and pore sizes $(11.1-8.7 \mathrm{~nm})$ by increasing GPTMS content (2-4 molar ratio GPTMS:CS monomer). In addition, samples exhibited extremely fast swelling by spontaneous capillary imbibition in PBS solution, presenting swelling capacities from 1.75 to 3.75. The formation of a covalent crosslinked hybrid structure was suggested by FTIR and confirmed by an increase of four hundred fold or more in the compressive strength up to $96 \mathrm{MPa}$. Instead, samples synthesized without GPTMS fractured at only $0.10-0.26 \mathrm{MPa}$, revealing a week structure consisted in interpenetrated polymer networks. The aerogels presented bioactivity in simulated body fluid (SBF), as confirmed by the in vitro formation of hydroxyapatite (HAp) layer with crystal size of approximately $2 \mu \mathrm{m}$ size in diameter. In vitro studies revealed also non cytotoxic effect on $\mathrm{HOB}^{\circledR}$ osteoblasts and also a mechanosensitive response. Additionally, control cells grown on glass developed scarce or no stress fibers, while cells grown on hybrid samples showed a significant $(p<0.05)$ increase in well-developed stress fibers and mature focal adhesion complexes.
\end{abstract}

Keywords: hybrid silica aerogels; chitosan; GPTMS; textural properties; mechanical properties; swelling properties; bioactivity; bone tissue engineering; osteoblasts; focal adhesions

\section{Introduction}

A new generation of bio-based aerogels has been attracted much attention research during the last two decades, particularly in emerging areas associated to environmental and biomedical sciences [1-5]. Thanks to their unique and tuneable properties, as well as ease of functionalization, a widespread range 
of applications has been proposed and developed for silica-based biopolymer aerogels [6]. Moreover, their characteristic 3D open network structure facilitates the access for external fluids, which allows a controlled interaction with internal active surfaces and/or encapsulated secondary phases. Due to its versatility, these type of materials have been proposed for very different applications, such as catalysis [4], $\mathrm{CO}_{2}$ capture [7], oil-water separation [8], drug delivery and medicine [9]. In this context, a well-diversified collection of biopolymers has been considered for the preparation of bio-aerogels, including collagen [10], gelatin [11], whey proteins [12], etc. Also polysaccharides such as alginate [13], cellulose [14], chitosan (CS) [15] and many others have been successfully used to produce bio-based aerogels $[16,17]$. Among the natural compounds, CS (a biopolymer extracted from chitin natural source) has attracted great interest due to their remarkable properties for industrial technology and biomedical fields [18-20].

Besides, extensive research has been conducted on the chemical modifications of chitosan, as summarized in numerous and excellent publications focused on this topic [21-24] Hence, the hybridization of CS with an inorganic silica network by using sol-gel method has been investigated so far, as a strategy to achieve improved properties from a combined synergistic effect of the properties of the individual organic and inorganic component $[15,25]$. Moreover, silica is considered to be a decisive part of the mechanism of biomineralization of biomimetic apatite on bioactive surfaces [26], so it may help to stimulate adequate biological response in biomaterials. Regarding this issue, silanol groups in the surface acts a nucleation sites together with factors related with the textural characteristics of the materials, thus controlling the mechanism for nucleation and growth of biomimetic hydroxyapatite layer [27]. Therefore, silica-based hybrid aerogel structures, presenting tunable mechanical and chemical properties, may also improve the primary characteristics of biomaterials: non-cytoxicity, biocompatibility, bioactivity, biodegradability, etc. $[28,29]$. Consequently, hybrid aerogels in the CS-silica system are expected to improve mechanical strength as well as biological properties of the resulting biomaterials in the field of biomedical engineering.

To date, various CS-silica aerogel synthesis processes have been reported and, in general, all of them involved a mixture of sol-gel precursors followed by the formation of the hybrid gel [25,30-32] The subsequent extraction of the pore filling liquids from the wet gels is the most important step for obtaining the hybrid aerogels, which has been usually accomplished by supercritical drying $[31,33]$ However, also freezing drying [34] or ambient pressure drying [25] methods have been successfully employed. The first reported fabrication of CS-silica hybrid monolithic aerogels using $\mathrm{CO}_{2}$ supercritical drying was performed by Ayers and Hunt [15], who described the influence of CS on the physical properties and the biocompatibility of the resulting aerogels. After a thorough investigation of the topic, CS-silica aerogels were proposed for different applications and here we will take special consideration of biomaterials for biomedical purposes $[1,2,20,26,35,36]$

To this end, many research studies presented in the literature about the synthesis of chitosan-silica hybrids proposed the use of crosslinking agents, to create strong interactions at nanoscale with creation of covalent bonds between chitosan and silica network [37]. This strategy is favored by the presence of both hydroxyl and primary amine groups in chitosan molecule (a heteropolymer made of glucosamine and $\mathrm{N}$-acetyl glucosamine), that facilitates the introduction of coupling agents. Best reported results were observed using 3-glycidoxypropyl trimethoxysilane (GPTMS), one of the most frequently used alkoxysilanes to synthesize class II hybrid materials $[37,38]$ according to the hybrid classification of Gomez-Romero and Sanchez [39] In acidic aqueous solution, GPTMS may proceeds to functionalize chitosan creating covalently bonded compounds, according to different reaction mechanisms (see Figure 1) [40,41]. So, for example, through the nucleophilic attack by the primary amine group of chitosan to open the epoxide ring, (route 1); by condensation of silane groups of GPTMS with hydroxyl groups of chitosan (route 2); through nucleophilic attack by the hydroxyl groups of the chitosan to open the epoxide ring (route 3). In addition, some ionic chemical species can be formed too between positively charged amine groups and negatively charged silanes, or negatively charged oxygen from the epoxide group. In all cases, the methoxysilane groups hydrolyzed to form 
silanol groups simultaneously, as shown in Figure 1, and may eventually condense with the silica network developed from the corresponding inorganic component of the hybrid, to form the $\mathrm{Si}-\mathrm{O}-\mathrm{Si}$ covalent bonds and thus creating a crosslinked mechanically reinforced structure.

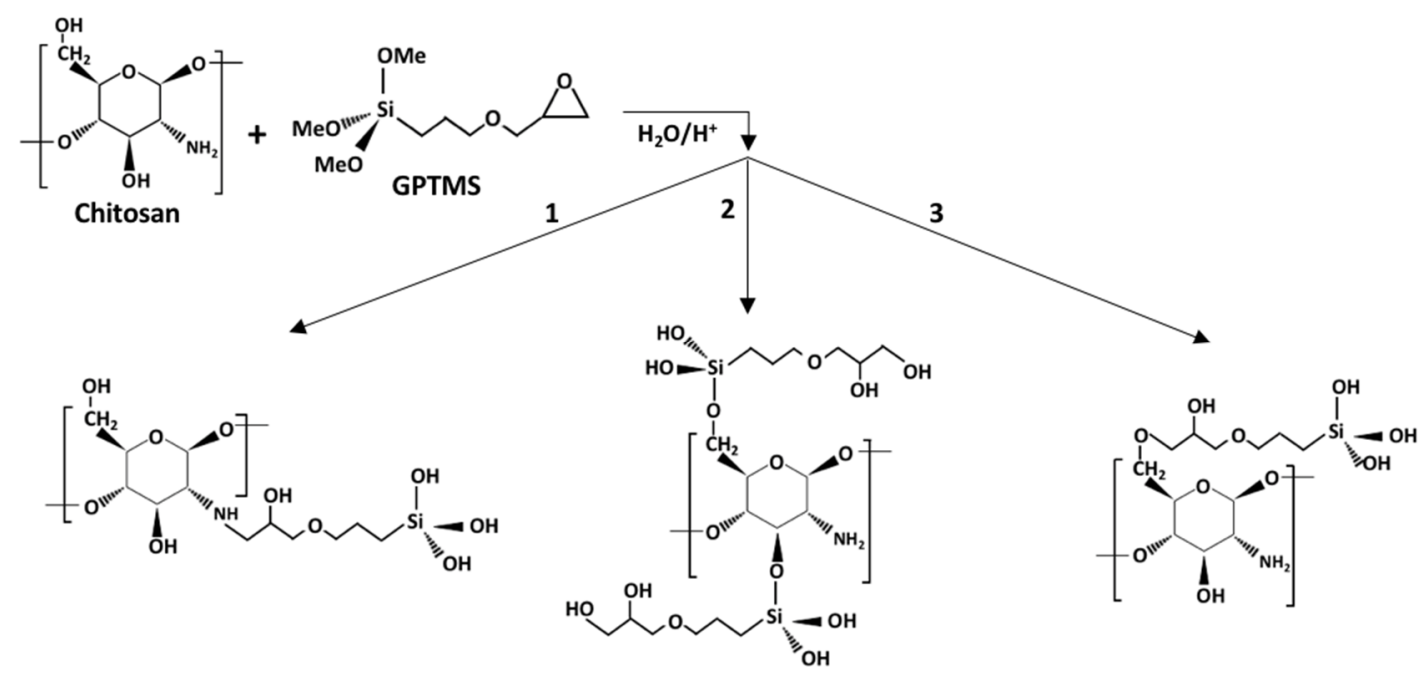

Figure 1. Alternatives routes of functionalization of deacetylated chitosan by GPTMS in acidic medium. (1) Trough nucleophilic attack of epoxide ring by amine group of chitosan; (2) by condensation of silanol and $\mathrm{OH}$ groups of chitosan; (3) by nucleophilic attack of epoxide by $\mathrm{OH}$ group of chitosan [40].

Additionally, several studies have focused on the preparation of CS-silica hybrid materials using tetraethoxysilane (TEOS) as silica source and GPTMS crosslinker, reporting the formation of covalent bonding between silica and CS networks $[40,41]$. The resulting materials were intended for drug delivery technology [42-44] but also as separation membranes in biomaterials [45]. Other authors obtained interpenetrating network hybrid membranes made of silica and CS instead, without using crosslinking agents [46]. Nevertheless, despite significant achievements in the preparation and characterization of CS-silica hybrids for biomedical purposes, and the hundreds of articles related to this topic, more efforts are needed to evaluate the potential applications of their corresponding mesoporous aerogels as biomaterials for tissue engineering.

The current study suggests that chitosan-silica mesoporous aerogels has osteoregenerative properties. To this end, we synthesized monolithic hybrid aerogels by sol-gel followed by supercritical $\mathrm{CO}_{2}$ drying, based on chitosan (CS) and two types of alkoxysilanes: TEOS, as silica inorganic precursor, and GPTMS, as crosslinker agent, used in different molar ratios. We prepared several formulations of hybrid aerogels incorporating different amounts of chitosan and GPTMS and examined the effect of their compositions on the structure, mechanical and swelling properties. In addition this work investigates the in vitro bioactivity of the hybrid materials in simulated body fluid (SBF), as well as the osteoblast cell response of the hybrids by in vitro culture methods.

\section{Materials and Methods}

\subsection{Materials}

Tetraethylortosilicate (TEOS, 99\%) and Chloride acid $(\mathrm{HCl})(37 \%)$ were obtained from Alfa Aesar (Haverhill, MA, USA). Chitosan (CS; 50,000-190,000 Da; 75\%-85\% deacetylation degree) and 3-glycidoxypropyltrimethoxysilane (GPTMS, >98\%) were purchased for Sigma Aldrich (St. Louis, MO, USA). Absolute ethanol (99.5\%) was purchased from Panreac (Barcelona, Spain). Acid acetic (Reagent Grade) was purchased for Scharlau (Barcelona, Spain). HOB ${ }^{\circledR}$ human osteoblasts, foetal calf serum and Osteoblast Growing Medium (Promocell, Heidelberg, Germany). Paraformaldehyde, PBS, Triton x-100, bovine serum albumin, Metanol, rhodamine phalloidin and monoclonal anti-vinculin 
FITC conjugate were all purchased from Sigma, (St. Louis, MI, USA), Vectashield ${ }^{\circledR}$ (Vector, Burlingame, CA, USA).

\subsection{Synthesis of TEOS and CS-GPTMS Precursor Sols}

CS-silica and CS-GPTMS-silica hybrid aerogels were fabricated with different compositions using the sol-gel method by mixing two precursor sols. The first one made of hydrolysed TEOS with the stoichiometry acid water and the second one was prepared by mixing low molecular weight chitosan and GPTMS (where necessary) in aqueous acetic acid solution. The diagram in Figure 2 summarizes the key steps of the complete synthesis process.

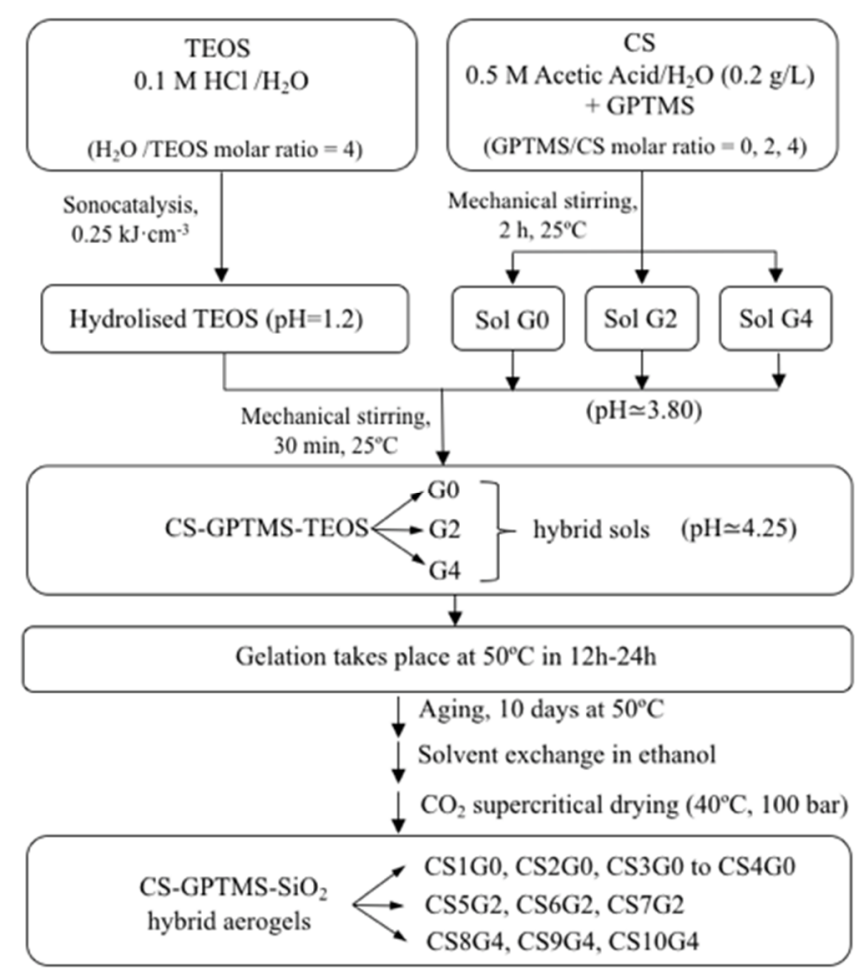

Figure 2. Scheme of the synthesis procedure. In total, ten hybrid aerogels were prepared, denoted as CSnGx ( $\mathrm{n}$ is a code number that goes from 1 to 10 and $\mathrm{x}=0,2,4$, indicates the GPTMS/CS monomer molar ratio).

First, TEOS was totally hydrolysed with stoichiometric quantity of $0.1 \mathrm{~N} \mathrm{HCl}$ under the catalyst effects of ultrasound, by supplying $0.25 \mathrm{~kJ} / \mathrm{cm}^{3}$ of sonic power using a Vibracell 500 Watt ultrasonic processor from Sonics \& Materials (Newtown, CT, USA). A second sol was obtained by dissolving CS powder in $0.5 \mathrm{M}$ aqueous acetic acid solution under vigorous stirring for $2 \mathrm{~h}$ at $25^{\circ} \mathrm{C}$ to produce $2 \%$ $w / v$ CS solution. Then, different amounts of GPTMS were added drop-wise to this CS solution with 30 min additional mechanical stirring at $25^{\circ} \mathrm{C}$, in order to functionalize the CS biopolymer. In contrast, the preparation of a CS solution without the addition of GPTMS was contemplated. In summary, four sols were obtained: an aqueous silica sol $(\mathrm{pH}=1.2)$ from TEOS, and three additional GPTMS-CS sols with different molar ratios GPTMS:CS monomer: 0 (no GPTMS), 2 and 4 ( $\mathrm{pH} \sim 3.80$ ).

\subsection{Synthesis of CS-GPTMS-Silica Hybrid Aerogels Monolith}

The preparation of hybrid aerogels continued by mixing separately the three CS-GPTMS sols with the hydrolyzed TEOS until homogenization, under mechanical stirring at $25^{\circ} \mathrm{C}$ for $30 \mathrm{~min}$. Several inorganic/organic (chitosan) weight ratios and molar ratios of TEOS, CS and GPTMS were examined, as shown in Table 1, where the detailed synthetic conditions used in this work are presented. 
Table 1. Sample identification, starting compositions and final content of CS based on Elemental Analysis (EA) measured data for each synthesized aerogel.

\begin{tabular}{ccccc}
\hline $\begin{array}{c}\text { Sample } \\
\text { Identification }\end{array}$ & $\begin{array}{c}\text { Nominal CS } \\
\text { Content }\end{array}$ & GPTMS/CS & TEOS/CS & $\begin{array}{c}\text { Final CS Content } \\
\text { from EA }\end{array}$ \\
\hline (wt\%) & (Molar Ratio) & (Molar Ratio) & $\mathbf{( w t \% )}$ \\
\hline CS1G0 & 3.8 & 0 & 150 & 1.7 \\
CS2G0 & 7.3 & & 75 & 3.3 \\
CS3G0 & 12.3 & & 45 & 7.6 \\
CS4G0 & 16.7 & 2 & 30 & 10.3 \\
\hline CS5G2 & 3.7 & & 150 & 3.1 \\
CS6G2 & 6.8 & & 75 & 5.9 \\
CS7G2 & 14.2 & 4 & 30 & 8.0 \\
\hline CS8G4 & 6.3 & & 75 & 3.1 \\
CS9G4 & 9.8 & & 45 & 5.3 \\
CS10G4 & 12.3 & & 30 & 9.7 \\
\hline
\end{tabular}

${ }^{1}$ Final CS content was calculated from the $\mathrm{N}$ values measurements in EA, considering that chitosan is the sole source of nitrogen in the samples.

The samples with $x=0$ were obtained without coupling agent GPTMS, as a reference, being named CSnG0. In total, ten aerogels with several TEOS/CS and GPTMS/CS molar ratios were prepared and characterized. Subsequently, the freshly prepared CS-GPTMS-TEOS sols $(\mathrm{pH} \sim 4.25)$ were transferred to $5 \mathrm{~mL}$ cylinder-shaped plastic vials and left hermetically closed at $50{ }^{\circ} \mathrm{C}$ in an oven, until the gels were set. Following, the resulting alcogels were soaked in ethanol excess at $50{ }^{\circ} \mathrm{C}$ for 10 days for aging and removing the residual water from the pore. Finally, wet gels were dried in supercritical $\mathrm{CO}_{2}$ at $40^{\circ} \mathrm{C}$ and $10 \mathrm{MPa}$, to obtain the monolithic hybrid aerogels.

\subsection{Physical and Textural Characterisation}

The density of the samples was obtained by measuring the mass and the size of the monolithic cylindrical samples with a sliding calliper and a microbalance (precision $\pm 0.1 \mathrm{mg}$ ). The textural properties of the hybrid aerogels were investigated by means of nitrogen physisorption experiments (Micromeritics ASAP2010, Norcross, GA, USA), working at $77 \mathrm{~K}$ and equipped with pressure transducer resolution of $10^{-4} \mathrm{~mm} \mathrm{Hg}$ ). Specific surface area, pore volume and pore size distribution were determined, considering BET and BJH standard models for the analysis. Prior to these experiments, samples were degasified at $120^{\circ} \mathrm{C}$ for $6 \mathrm{~h}$.

\subsection{Thermal Characterization}

Thermogravimetric analysis (TGA) was performed with a TGA Q50 from TA Instruments (New Castle, DE, USA) in order to determine the stability of the sample as a function of temperature. The sample heating rate was $10^{\circ} \mathrm{C} \mathrm{min}^{-1}$ and a temperature ramp of 50 to $900{ }^{\circ} \mathrm{C}$ under air atmosphere was used to completely resolved all the weight loss events.

\subsection{FT-IR Spectroscopy}

FTIR was performed on a Bruker Tensor 37 spectrophotometer (Billerica, MA, USA). The spectra were recorded at room temperature with a resolution of $4 \mathrm{~cm}^{-1}$ and 100 scans in the region from 500 to $4000 \mathrm{~cm}^{-1}$ The samples were stored $24 \mathrm{~h}$ at $60{ }^{\circ} \mathrm{C}$, then ground into fine powder, mixed with $\mathrm{KBr}$ and pressed into a self-supporting wafer which was put on a sample holder for spectrum measurement.

\subsection{Swelling Behavior-PBS Swelling Capacity}

The swelling ratio of hybrid aerogels was studied to evaluate their swelling behavior and mechanical stability under aqueous medium. To investigate the hybrid network ability to absorb, dry sample monoliths ( $5 \mathrm{~mm}$ high and $8-10 \mathrm{~mm}$ in diameter) were immersed into $30 \mathrm{~mL}$ phosphate 
buffer solution (PBS; $\mathrm{pH}=7.4$ ) at room temperature. The swelling ratio $S R$ of the samples was defined as the weight increase, per unit weight of the original dry hybrid aerogel, due to PBS aqueous solvent absorption. It was calculated in grams of the liquid absorbed PBS per grams of dry sample using Equation (1)

$$
S R=\frac{W_{t}-W_{d}}{W_{d}}
$$

where $W_{d}$ and $W_{t}$ correspond to the weights of the sample in dry and in swollen states at time $t$, respectively. Experiments were performed in triplicate using a $30 \mathrm{~mm}$ inner diameter basket made of $2 \mathrm{~mm}$ aperture stainless steel wire mesh, which was carefully dried for each measurement. Weight measuring was carried out by first blotting both the aerogel surface and the wire basket with filter paper, to remove excess surface PBS, and then weighed immediately. The process was repeated several times at different time intervals, until the sample saturation point $W_{\infty}$ was reached and did not indicate any weight change.

\subsection{Swelling Kinetics}

Besides quantifying the swelling capacity effects for the hybrid aerogels, the knowledge of the swelling kinetics can also be important to evaluate their applicability as porous materials for tissue repair, as it gives information on the rapidity for filling and repairing some bone defects for certain applications [43]. Hence the investigation of the swelling rate for hybrid aerogels should be accomplished. To this end, the absorption behavior was described by the normalized absorption ratio $M^{*}(t)$ and was plotted versus $\sqrt{ } t$. This square-root-of-time dependency suggested denotes a Lucas-Washburn model for absorption kinetics [47], typical of fast imbibition of liquids by capillary rise, considering a rigid porous structure. The Equation (2) was used:

$$
M^{*}(t)=\frac{W_{t}-W_{d}}{W_{\infty}}
$$

where $W_{\infty}$ is the weight of saturated sample.

\subsection{Mechanical Properties}

Mechanical properties of samples were characterized by uniaxial compression (Shimadzu AG-I Autograph, Kyoto, Japan) with a load cell of $5 \mathrm{kN}$ for dry samples and of $50 \mathrm{~N}$ for samples immersed in PBS. Cylindrical samples $16-20 \mathrm{~mm}$ high and $8-10 \mathrm{~mm}$ in diameter were used, fulfilling with ASTM D7012 $(\mathrm{h}=2 \mathrm{D})$. The compressive strength and maximum strain were obtained from the maximum deformation before the fracture of the sample, and the elastic modulus from the initial tangent of the stress-strain curve.

\subsection{In Vitro Bioactivity}

Biomineralization was studied by submerging $5 \mathrm{~mm}$ length $\times 8 \mathrm{~mm}$ diameter aerogel pellets in $30 \mathrm{~mL}$ simulated body fluid SBF in polyethylene containers, through the analysis of hydroxyapatite (HAp) formation at the surface. SBF was prepared according to Kokubo's method [48] and soaking was maintained for 21 days at $37^{\circ} \mathrm{C}$. The test was performed with fluid weekly exchange and samples were taken out from the buffer solution after every 7 days, carefully washed with Milli-Q (MilliporeSigma, Burlington, MA, USA) for removing surface minerals and later again dried at $50{ }^{\circ} \mathrm{C}$ and ambient pressure. Surface morphologies of SBF treated samples after different soaking periods were investigated with SEM/FEI Nova NanoSEM 450 (FEI, Morristown, NJ, USA); (resolution $1.4 \mathrm{~nm}$ ) equipped with a Bruker SDD-EDS detector, used for determining $\mathrm{Ca} / \mathrm{P}$ compositional differences across the specimen surface. High resolution imaging HRTEM was performed with TEM TALOS FX200 (Thermo Scientific, Waltham, MA, USA) and selected-area electron diffraction (SAED) patterns were obtained in microprobe mode, in order to identify the crystalline nature of possible nanocrystalline phases. 


\subsection{In Vitro Biocompatibility}

HOB $^{\circledR}$ human osteoblasts (Promocell, Heidelberg, Germany) were seeded at a density of 15,000 cells $/ \mathrm{cm}^{2}$ and incubated in Osteoblast Growing Medium supplemented to a final concentration of $0.1 \mathrm{~mL} / \mathrm{mL}$ of fetal calf serum (Promocell) at $37^{\circ} \mathrm{C}$ and $5 \% \mathrm{CO}_{2}$ on test surfaces and immunolabelled after $48 \mathrm{~h}, 72 \mathrm{~h}$ and 1 week. Growth medium was changed every two days. HOB cells did not exceed ten population doublings. Aerogels were sterilized in autoclave in order to achieve optimal sterilization, prior to cell seeding. At least five samples of each type were seeded and analyzed per experiment. The test groups for selected samples with higher CS content were as follows: CS4G0, CS7G2 and CS10G4. HOB ${ }^{\circledR}$ cells grown on glass were used as control.

\subsubsection{Cell Morphology and Spreading}

Cells were daily examined with the phase contrast microscope in order to evaluate cell morphology, alignment and initial adhesion phase to surfaces. Morphological changes, cell distribution and spreading were assessed prior to immunolabelling for fluorescence and CLSM examination of the CS4G0, CS7G2 and CS10G4 samples.

\subsubsection{Actin Cytoskeletal Organization and Vinculin Expression}

At the end of each experiment, cells were washed with prewarmed phosphate buffered saline (PBS), $\mathrm{pH} 7.4$, and fixed with $3.7 \%$ paraformaldehyde at room temperature, washed, and then permeabilized with $0.1 \%$ Triton $x-100$ ). After washing, cells were preincubated with $1 \%$ bovine serum albumin (Sigma) in PBS for 20 min prior to cell immunolabelling for actin cytoskeleton with rhodamine phalloidin (Sigma) and monoclonal anti-vinculin FITC conjugate (Sigma). After $20 \mathrm{~min}$. $\mathrm{TiO}_{2} / \mathrm{PLGA}-10$, $\mathrm{TiO}_{2} / \mathrm{PLGA}-3, \mathrm{TiO}_{2} / \mathrm{PLGA}-100$ samples were rinsed with prewarmed PBS prior to mounting with Vectashield ${ }^{\circledR}$ (Vector, Burlingame, CA, USA).

\subsubsection{Confocal Examination}

Samples were visualized using an Olympus confocal microscope (Tokyo, Japan). At least five samples were analyzed for each group to assess surface influence on cytoskeletal organization, focal adhesion number, and development and cell morphology. Images were collected and processed using imaging software. At least 50 cells per sample were analyzed. Samples were exposed to the lowest laser power that was able to produce a fluorescent signal for a time interval not higher than $5 \mathrm{~min}$ to avoid photobleaching. A pinhole of 1 Airy unit was used. Images were acquired at a resolution of $1024 \times 1024$, mean voxel size of $209.20 \mathrm{~nm}$.

\subsubsection{Image Analysis}

To analyze the differences in focal adhesion number between different sample groups, images were collected as frames obtained at $40 \times$ magnification and processed using Image J software. All experiments were repeated in triplicate, unless otherwise stated. All data were SPSS analyzed and expressed as mean \pm standard deviation. For the variable number of contacts, a descriptive analysis was used to summarize the number of contacts in each experimental group, and a two-way ANOVA and Tukeys comparison of means were employed. Statistical significance was defined as $p<0.05$.

\section{Results and Discussion}

\subsection{Synthesis of CS-GPTMS-Silica Hybrid Aerogels}

CS-SiO ${ }_{2}$ and CS-GPTMS-SiO ${ }_{2}$ monolithic hybrid aerogels were here synthesized by sol-gel techniques. The specimens were elastic and mechanically resistant upon handling and homogeneous throughout the bulk, suggesting a well distribution and incorporation of the chitosan and silica 
components, as shown in Figure S1 of Supplementary materials. The influence of both CS and GPTMS on the structure, mechanical and biological activity of the hybrids was studied.

The suggested reaction mechanisms between CS and GPTMS were previously described in Figure 1 and as result of the crosslinking reaction for G2 and G4 aerogel series, a class II hybrid copolymer network was produced [40]. In its place, hybridization without the silane-coupling agent (G0 aerogel series) could lead to the formation of interpenetrating network hybrid aerogels, featuring class I hybrid structure [39], with rigid silica 3D mesoporous structure and swellable CS moieties. Under these conditions, CS would even get involved in condensation reaction with silanol groups to create Si-O-C bonds with carbonyl groups of the polysaccharide.

Code samples and theoretical compositions are shown in Table 1. The remaining content for CS at the end of the synthesis process is also listed and was calculated based on nitrogen Elemental Analysis (EA) data, obtained from dry aerogels. Although CS nominal content ranged from 3.7 to about $16.7 \mathrm{wt} \%$ loading, the results show that only a fraction remained at the end of the synthesis. As consequence, the final composition of the hybrids was not well controlled by the amount of CS, due to its dissolution and leaching in the acid media. Additionally, the tendency of GPTMS to diol formation in acid aqueous media, resulting in deactivation of its cross-linking capacity, was also responsible for the observed decreasing CS contents respect to their theoretical compositions [41]. Though, it was possible to obtain a series of hybrid aerogels with different CS and GPTMS concentrations, providing us to study the influence of both components on the structural and mechanical properties of the hybrids.

\subsection{Bulk Density and Textural Properties}

We estimated the bulk densities of the samples for different CS and GPTMS contents by using geometric measurements. Table 2 and Figure 3 a displays the corresponding values for all of the samples studied. A decreasing trend in the density of G0 aerogels series, from the $\rho=0.38 \mathrm{~g} \mathrm{~cm}^{-3}$ of CS1G0 sample (CS $1.7 \mathrm{wt} \%$ ) to the $\rho=0.17 \mathrm{~g} \mathrm{~cm}^{-3}$ for both CS3G0 CS (7.6 $\mathrm{wt} \%$ ) and CS4G0 (CS 10.30 $\mathrm{wt} \%)$ samples, reflects macroscopically the progressive incorporation of the chitosan. For the G2 aerogels series the same decreasing trend in density can be observed. However, the corresponding density values showed a narrower variation range, from $\rho=0.29 \mathrm{~cm}^{3} \mathrm{~g}^{-1}$ for CS5G2 (3.1 wt $\%$ CS) to $\rho=0.22 \mathrm{~cm}^{3} \mathrm{~g}^{-1}$ for CS6G2 $(5.9 \mathrm{wt} \% \mathrm{CS})$, respectively. These changes reveal the cross-linking action of GPTMS which contributes to the regularization of the hybrid structure. This normalization effect provided by the cross-linker is also observed in the G4 samples series but, in this case, the amount increase of CS determines a slight increase in bulk density, which goes from $0.31 \mathrm{~cm}^{3} \mathrm{~g}^{-1}$ for CS8G4 (3.1 $\mathrm{wt} \% \mathrm{CS}$ ) up to $0.37 \mathrm{~cm}^{3} \mathrm{~g}^{-1}$ for CS10G4 (9.7 $\mathrm{wt} \% \mathrm{CS}$ ) samples.

Table 2. Bulk density and textural data from $\mathrm{N}_{2}$ physisorption for CS-GPTMS-Silica hybrid aerogels.

\begin{tabular}{|c|c|c|c|c|c|}
\hline \multirow[b]{2}{*}{ Sample } & \multirow[b]{2}{*}{$\begin{array}{c}\text { Density } \\
\left( \pm 0.01 \mathrm{~g} \mathrm{~cm}^{-3}\right)\end{array}$} & \multicolumn{4}{|c|}{ Physisorption } \\
\hline & & $\begin{array}{c}S_{B E T} 1 \\
\left(m^{2} g^{-1}\right)\end{array}$ & $\begin{array}{l}\text { Pore Volume } \\
\left(\mathrm{cm}^{3} \mathrm{~g}^{-1}\right)\end{array}$ & Pore Size (nm) & Porosity (\%) \\
\hline CS1G0 & 0.38 & 1184 & 2.6 & 8.1 & 81.9 \\
\hline CS2G0 & 0.26 & 1230 & 3.4 & 10.2 & 87.6 \\
\hline CS3G0 & 0.17 & 811 & 2.3 & 10.2 & 82.4 \\
\hline CS4G0 & 0.17 & 755 & 1.9 & 11.1 & 91.6 \\
\hline CS5G2 & 0.29 & 1042 & 3.1 & 11.2 & 86.1 \\
\hline CS6G2 & 0.22 & 903 & 3.2 & 14 & 89.3 \\
\hline CS7G2 & 0.23 & 771 & 2.2 & 11.6 & 89.1 \\
\hline CS8G4 & 0.31 & 955 & 2.1 & 8.7 & 85.4 \\
\hline CS9G4 & 0.32 & 697 & 1.6 & 8.9 & 82.6 \\
\hline CS10G4 & 0.37 & 695 & 1.7 & 9.8 & 82.3 \\
\hline
\end{tabular}



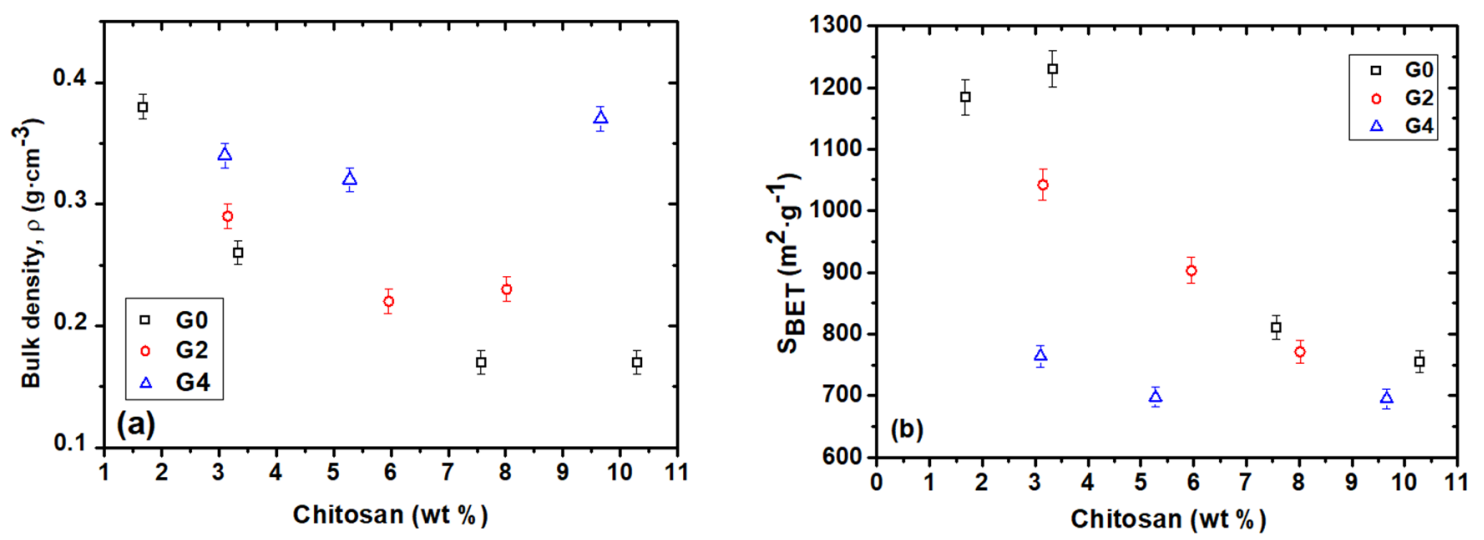

Figure 3. (a) Bulk density and (b) BET surface area of the CS-GPTMS-silica hybrids as a function of CS content (wt $\%)$ obtained from EA.

Besides, as a consequence of the CS addition and also that of the GPTMS cross-linker, the hybrid aerogels tend to feature lower BET surface area, varying from $1230 \mathrm{~m}^{2} \mathrm{~g}^{-1}$ (CS2G0) to above $700 \mathrm{~m}^{2} \mathrm{~g}^{-1}$ (CS10G4) (Figure 3b). Thus, it was found that aerogels with higher crosslinker content (CS8G4, CS9G4 and CS10G4) presented the lowest surface area values. However, although pore volume and pore size data did not follow an uniform trend, it can be concluded that the gradual inclusion of chitosan inside the porous volume of the silica porous matrix (from $1.7 \mathrm{wt} \%$ to above $8-10 \mathrm{wt} \%$ ), joined to an increase of the crosslink density, produced a reduction of the porous volume from $2.6 \mathrm{~cm}^{3} \mathrm{~g}^{-1}$ (CS1G0) to $1.7 \mathrm{~cm}^{3} \mathrm{~g}^{-1}$ (CS10G4). Meanwhile, pore size experimented a slight increase from $8.1 \mathrm{~nm}$ to $11.1 \mathrm{~nm}$ for G0 aerogel series, $11.2 \mathrm{~nm}-14 \mathrm{~nm}$ for G2 series and $8.7 \mathrm{~nm}$ to $9.8 \mathrm{~nm}$ for G4 series. In addition, the porosity was calculated following Equation (3):

$$
\% \text { porosity }=\left(1-\frac{\rho_{\text {bulk }}}{\rho_{\text {skeleton }}}\right) \times 100
$$

where $\rho_{\text {bulk }}$ is the bulk density and $\rho_{\text {skeleton }}$ is the density of a silica matrix. $\left(2.09 \mathrm{~g} \mathrm{~cm}^{-3}\right)$ [49]. The corresponding porosity values ranged from $81.9 \%$ to $91.6 \%$ for CS1G0 and CS4G0 samples, respectively, and are presented in Table 2, together with the most relevant values of the structural parameters.

$\mathrm{N}_{2}$-physisorption isotherms of CS1G0, CS4G0, CS7G2 and CS10G4 selected samples with 1.7, 10.3, 8.00 and $9.7 \mathrm{wt} \%$ CS content, respectively, are shown in Figure S2 (in the Supplementary Materials). We found that this selection of low and high organic and GPTMS content, was representative for describing the structural properties of the obtained aerogels. According to the IUPAC classification all of these samples exhibited type IV isotherms, with a hysteresis loop that determine the presence of interconnected network of mesopores [50], by which multilayer adsorption as it proceeds through capillary condensation process.

A type $\mathrm{H} 1$ hysteresis loop, characteristic of materials with uniform pores and narrow pore size distributions (PSD), according to previous structural studies on silica aerogels [51] is observed for the CS1G0 isotherm curve. A change to a type H2 hysteresis loop (CS4G0, CS7G2 and CS10G4 aerogels) was observed by the concurrence of a plateau at high relative pressure (0.9-0.95). This is a sign of the existence of a highly interconnected complex pore network hybrid structure and as a result the pores have a large range of size and shape (Figure 3b). However, as expected, CS1G0 shows a narrow PSD as corresponds to an almost pure silica aerogel (see inset in Figure S2b in the Supplementary Materials).

Also, the well-defined plateau in the CS10G4 isotherm leading to a steep desorption towards low relative pressures is indicative of a desorption process that takes place over only a small pressure range for all pores. However, this plateau is not so well defined for the CS4G0 and CS7G2 isotherms, leading to a further gradual increase of amount adsorbed at high relative pressure (see inset of Figure S2a). This is consistent with the onset of capillary condensation at higher pressures for wider mesopores, 
as can be seen in Figure S2b (Supplementary Materials) that depicts the PSD obtained by BJH analysis of the desorption branch of the isotherms.

\subsection{Fourier Transformed Infra-Red (FTIR) Spectral Analysis}

The FTIR spectrum of the CS1G0, CS4G0, CS7G2 and CS10G4 hybrid aerogels showed seven major peaks corresponding to the following wavenumbers 800, 950, 1090, 1520, 1640, 2900 and $3500 \mathrm{~cm}^{-1}$ as shown in Figure 4 and their bands' descriptions will be described below. FTIR spectra showed an intensive broad absorption band located at $1090 \mathrm{~cm}^{-1}$ showing intensity increase due to the absorption from the $\mathrm{Si}-\mathrm{O}-\mathrm{C}$ bonds, and a peak at $800 \mathrm{~cm}^{-1}$, associated to strong $\mathrm{Si}-\mathrm{O}-\mathrm{Si}$ stretching vibrations. Another band is positioned at $950 \mathrm{~cm}^{-1}$ featuring the non-bridging oxygens (Si-OH bonds) in the silica network $[40,52,53]$. This Si-OH band was most prominent in aerogels without GPTMS, (CS1G0 and CS4G0) associating silanol groups with TEOS precursor rather than with the crosslinker. The absorption peak centered at about $3400 \mathrm{~cm}^{-1}$ is assigned to free or adsorbed water and is accompanied by the peak observed at $1640 \mathrm{~cm}^{-1}$, a characteristic peak for the $\mathrm{Si}-\mathrm{OH}$ bond, accounting for the hydrophilic behavior of the silica aerogels $[52,53]$. Then, its relative intensity decreases as GPTMS content increases, as shown in Figure 4.

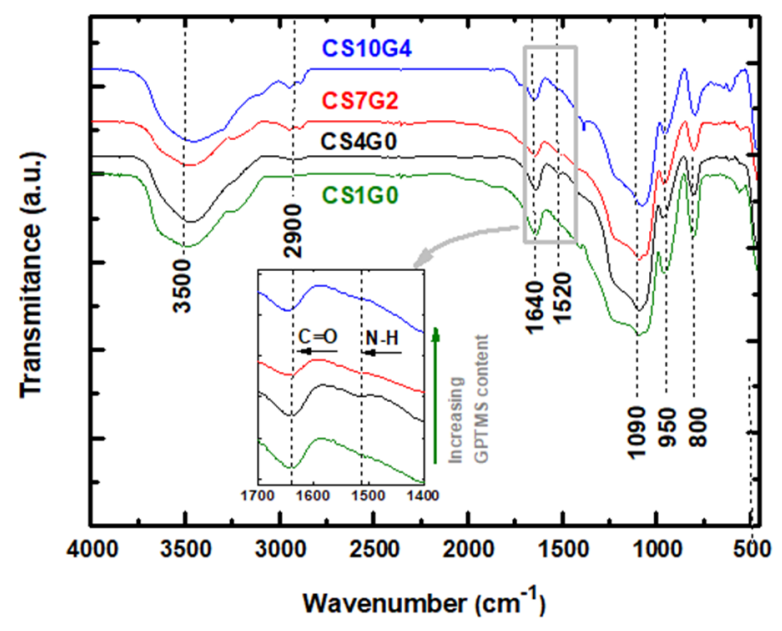

Figure 4. FTIR spectra of CS1G0, CS4G0, CS7G2 and CS10G4 hybrid aerogel samples.

Considering the covalent crosslinking between CS and silica network through silane-coupling agent GPTMS the region of interest is found in the range of $1660-1500 \mathrm{~cm}^{-1}[40,41]$. Chitosan powder has two absorption bands in this region: one at $1659 \mathrm{~cm}^{-1}$ due to the $\mathrm{C}=\mathrm{O}$ stretch of the secondary amide in acetylated units of chitosan and a second one small band at $1589 \mathrm{~cm}^{-1}$, related with $\mathrm{N}-\mathrm{H}$ bending of the primary amine in deacetylated units [54,55]. Due to the protonation of chitosan in acidic conditions both of these bands appeared, for the hybrid aerogel samples, slightly shifted from their original position, at $1640 \mathrm{~cm}^{-1}$ and $1520 \mathrm{~cm}^{-1}$, respectively (41) (see inset Figure 4). Moreover, overlapping of the the $\mathrm{C}=\mathrm{O}$ amide band at $1640 \mathrm{~cm}^{-1}$ with $\mathrm{Si}-\mathrm{OH}$ bond from silica network, makes it difficult to discern the mechanisms proposed for the formation of covalent links between functionalized chitosan and the silica network. However, the FTIR spectra from the studied samples exhibited a decrease of both amide bands with increasing GPTMS content at $1640 \mathrm{~cm}^{-1}$ and $1520 \mathrm{~cm}^{-1}$ (inset in Figure 4). Although these FTIR analyses are not conclusive to clearly discern the mechanisms proposed for the coupling between chitosan and GPTMS, these data would suggest the formation of $\mathrm{N}-\mathrm{C}$ bonding between chitosan and GPTMS. So far, there exists several mechanisms proposed for the coupling between chitosan and GPTMS implying the presence of different types of covalent bonds between the silica matrix and the functionalized chitosan [40]. 


\subsection{Thermogravimetric Analysis (TGA)}

The thermal stability and degradation behavior of the CS-GPTMS-Silica samples were evaluated by TGA under air atmosphere (see Figure S3; Supplementary Materials). Normally, the hybrids presented enhanced thermal stability for samples with high GPTMS content [25]. The TGA thermograms for the four hybrids CS1G0, CS4G0, CS7G2 and CS10G4 are relatively similar and show three steps of thermal degradation $[24,53]$. The first step started from above $60^{\circ} \mathrm{C}$ to $130{ }^{\circ} \mathrm{C}$. The peak at the DTG at above $90^{\circ} \mathrm{C}$ (see inset in Figure S3; Supplementary Materials) showed an initial dehydration weight loss of $7.55 \%$, referring to the physically adsorbed water surface of the polymer. This weight loss decreased with the increasing content for both chitosan and GPTMS. The second weight loss step was found between $130{ }^{\circ} \mathrm{C}$ and $220^{\circ} \mathrm{C}$ with maximum peak of $195^{\circ} \mathrm{C}$ in the DTG curve and corresponding mass losses increased from above $1.2 \%$ to $3.5 \%$ with increasing the chitosan content in the hybrid samples and it is referred to dihydroxylation of the silanols on the surface, (loss of chemically bound water) and decomposition of chitosan [54]. The third step of weight loss was subdivided in two parts, a first rapid and a second slow weight loss. First rapid weight loss appeared well differentiated between samples with and without GPTMS, and corresponds to the decomposition of the hybrid chains for G2 and G4 hybrids, between 220 and $500{ }^{\circ} \mathrm{C}$, with maximum DTG peak at $260^{\circ} \mathrm{C}$, and of the polysaccharide structure for samples without GPTMS (G0) $[24,53,56]$.

Second slow weight loss occurred between 450 and $800{ }^{\circ} \mathrm{C}$ reveals the complete decomposition of the organic components of the hybrids. For the first part, weight losses of $8.8 \%$ and $13.5 \%$ for CS1G0 and CS4G0 were observed, while $12 \%$ and $16 \%$ were estimated for CS7G2 and CS10G4, respectively. The second part for slow weight loss was above $4 \%$ and 5\% for CS7G2 and CS10G2, and around 2\% in the case of both CS1G0 and GS4G0 samples, without any range of weight stabilization.

\subsection{Swelling Behaviour-PBS Absorption}

The ability of hybrid samples to absorb phosphate buffered saline (PBS) solution was examined and the swelling curves for selected samples are reported in Figure 5a. All the experiments were done in triplicate to ensure reproducibility. As a general rule, it was observed that increasing the concentration of GPTMS decreases the swelling capacity [57] thus the aerogels presented total absorbed mass ratios ranging between 3.75 and 1.75 for CS7G2 and CS10G4, respectively. It is worth to note that these two samples were mechanically stable in the swollen state, exhibiting characteristic of class II hybrids. Instead, for CS1G0 and CS4G0 (class I hybrids), the swelling process provoked the appearance of multiple cracks at swelling equilibrium although they showed similar swelling capacities of 3.50 and 2.75, separately. These results highlights the importance of the mechanical control during swelling, to develop technical applications based on these samples $[32,58]$. These features will be studied in more detail in Section 3.7 .

Figure $5 \mathrm{~b}$ represents the swelling capacity versus CS content for different GPTMS/CS molar ratios and confirmed the influence of GPTMS on the swelling capacity, with G4 aerogel series (samples CS8, CS9 and CS10) showing more regular and lowest total absorption values (1.85-2.04). This was explained by the fact that increasing GPTMS made pore size to decreased (see Table 2) and the aerogel became more compact and highly crosslinked, which hinders swelling [32,57]. Summarizing, the affinity of the hybrid chains of the porous aerogels to the aqueous PBS, together with the swelling phenomenon observed in the hybrid structure, would be responsible for these high values of the absorption capacity obtained. 

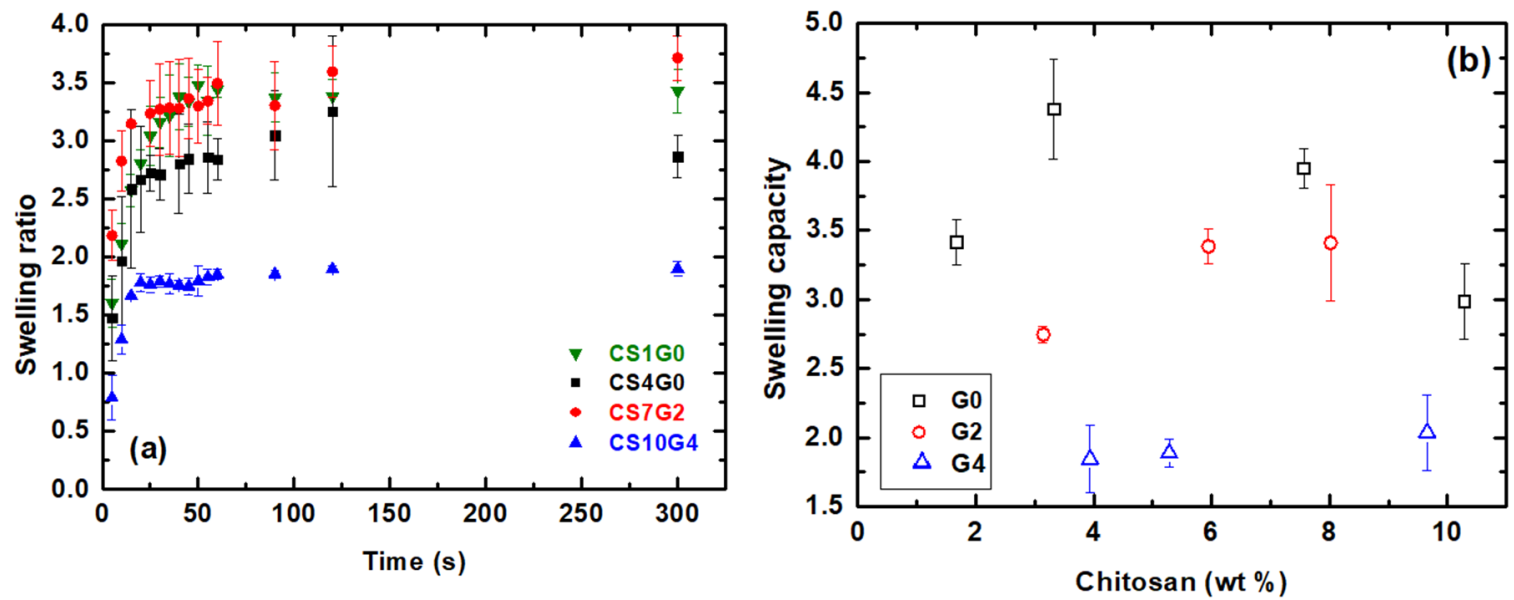

Figure 5. (a) Swelling ratio of CS1G0, CS4G0, CS7G2 and GS10G4 aerogels during liquid PBS absorption (b) Absorption capacity of CS/GPTMS-SiO2 hybrid aerogels in PBS.

\subsection{Absorption Kinetics}

The absorption behavior was described by the normalized absorption ratio $M^{*}(t)$ vs. $\sqrt{ } t$. It was found that the variation of the sample mass showed a root dependency of $t$, typical of fast imbibition of liquids by capillary rise, considering a rigid porous structure [51,59]. Also, it was observed that imbibition occurs almost instantaneously and is followed by a final regime toward saturation. The four representative curves for selected samples CS1G0, CS4G0, CS7G2 and CS10G4 are depicted in Figure 6 and all of them followed the $\sqrt{ } t$ classical-time dependence.

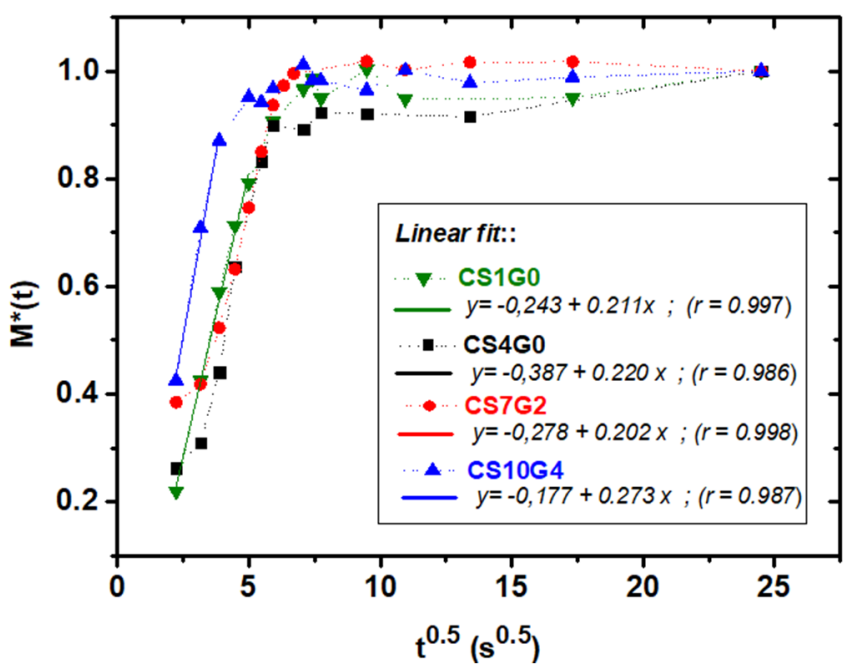

Figure 6. Normalized absorbed mass ratio for CS1G0, CS4G0, CS7G2 and GS10G4 aerogels during liquid PBS absorption versus square-root time. Lines correspond to linear fittings according to standard model of mass increase by imbibition due to capillary rise.

The linear fitting for each curve up to saturation shows well-defined initial linear regimes with similar slopes, revealing similar nanostructures and chemical composition of the porous network, with a slight steeper linear regime for CS10G4, indicating faster absorption, which must be related with its high crosslinking density. Further studies of the kinetic dependence of the absorption with the composition of these hybrids are in progress in order to completely resolve the absorption kinetics of the system. 


\subsection{Mechanical Properties-Uniaxial Compression}

The mechanical properties of the hybrids were analyzed on the samples before (dry) and after (wet) the PBS liquid absorption experiments. The uniaxial compression experiments provided an overall vision of the mechanical behavior of the hybrids, and the results obtained are summarized in Table 3, where Young's modulus, compressive strength and maximum compressive strain are reported. Stress-strain curves from rupture tests under uniaxial compression on selected samples CS1G0, CS4G0, CS7G2 and CS10G4 are plotted for dry (Figure S4a; Supplementary Materials) and wet samples (Figure S4b; Supplementary Materials). First, the stress-strain curves for dry states denoted the existence of two well-differentiated mechanical responses between samples incorporating the GPTMS and samples without the crosslinker.

Table 3. Mechanical properties obtained from the uniaxial compression testing of the dry samples and wet samples after saturation by the absorption of PBS for CS/GPTMS-Silica aerogels; mean values \pm standard deviation $(n=3)$.

\begin{tabular}{ccccccc}
\hline \multirow{2}{*}{ Sample } & \multicolumn{2}{c}{$\begin{array}{c}\text { Young's Modulus } \\
\mathbf{( M P a )}\end{array}$} & \multicolumn{2}{c}{$\begin{array}{c}\text { Compressive Strength } \\
\mathbf{( M P a )}\end{array}$} & \multicolumn{2}{c}{$\begin{array}{c}\text { Maximum Compressive Strain } \\
\mathbf{( \% )}\end{array}$} \\
\cline { 2 - 7 } & Dry & Wet & Dry & Wet & Dry & Wet \\
\hline CS1G0 & $11.2 \pm 1.4$ & $1.13 \pm 0.44$ & $1.0 \pm 0.3$ & $0.17 \pm 0.02$ & $12.2 \pm 2.3$ & $13.20 \pm 3.40$ \\
CS2G0 & $9.9 \pm 2.9$ & $0.30 \pm 0.10$ & $0.8 \pm 0.2$ & $0.07 \pm 0.01$ & $18.1 \pm 3.8$ & $13.47 \pm 0.21$. \\
CS3G0 & $1.9 \pm 0.1$ & $0.30 \pm 0.07$ & $16.1 \pm 4.2$ & $0.09 \pm 0.05$ & $66.4 \pm 7.0$ & $12.60 \pm 1.71$ \\
CS4G0 & $2.8 \pm 0.6$ & $0.75 \pm 0.25$ & $1.46 \pm 0.1$ & $0.11 \pm 0.04$ & $50.4 \pm 5.5$ & $9.18 \pm 1.55$ \\
\hline CS5G2 & $21.1 \pm 7.0$ & $0.78 \pm 0.07$ & $5.3 \pm 4.8$ & $0.19 \pm 0.05$ & $36.5 \pm 25.6$ & $12.92 \pm 1.30$ \\
CS6G2 & $7.7 \pm 1.5$ & $0.40 \pm 0.01$ & $22.6 \pm 15.1$ & $0.16 \pm 0.01$ & $77.6 \pm 16.3$ & $21.21 \pm 2.09$ \\
CS7G2 & $6.7 \pm 1.3$ & $0.16 \pm 0.02$ & $77.7 \pm 2.7$ & $0.09 \pm 0.03$ & $77.7 \pm 1.6$ & $22.89 \pm 9.47$ \\
\hline CS8G4 & $32.4 \pm 3.8$ & $0.77 \pm 0.30$ & $5.6 \pm 3.1$ & $0.21 \pm 0.01$ & $35.2 \pm 10.7$ & $9.41 \pm 3.01$ \\
CS9G4 & $8.7 \pm 0.5$ & $0.82 \pm 0.17$ & $5.5 \pm 2.9$ & $0.27 \pm 0.04$ & $38.0 \pm 14.9$ & $10.58 \pm 0.86$ \\
CS10G4 & $50.3 \pm 7.0$ & $0.27 \pm 0.03$ & $95.7 \pm 6.9$ & $0.26 \pm 0.03$ & $76.2 \pm 9.5$ & $21.74 \pm 1.37$ \\
\hline
\end{tabular}

In general, the increase in CS content is accompanied by a reduction in the elastic modulus and by structural strengthening of the dry aerogels [32]. At the same time, larger deformations were developed before rupture, indicating a brittle-ductile transition through elastomeric behavior, being more evident for higher GPTMS contents. An exception in Young's modulus progression is CS10G4, where the synergistic effects between the organic and inorganic hybrid components offers the highest compressive strength ( $96 \mathrm{MPa}$ ) and stiffness (50 MPa for Young's modulus) of all of the hybrid samples. Overall, these results indicate that a large increase in both, the compressive strength (more than 10-fold) and the maximum strain (more than 25-fold), was achieved for CS10G4, respect to previously reported for related samples [41].

More specifically, CS1G0 aerogel behaved as brittle material, showing relatively high elastic modulus (11.2 MPa) and low compressive strength (1.0 MPa) and maximum strain values $(12.2 \%)$. Increasing CS from 1.7 to $10.3 \mathrm{wt} \%$ (CS4G0) allowed to reach up to 50-60\% strain (inset Figure S4a; Supplementary Materials). Instead, samples incorporating GPTMS in their chemical structures (G2 and G4 aerogels) showed a rubber-like stress-strain behavior, with high elongation at break and non-linearity as its most obvious feature, typical of synthetic elastomers (CS7G2 and CS10G4 samples).

On the other hand, the uniaxial compression experiments performed under liquid absorption (Figure S4b; Supplementary Materials) led to degraded network structures which, in all cases, behaved as extremely soft materials. Young's modulus values were in the range (0.16-1.13) MPa and compressive strength between (0.07-0.27) MPa, showing two-three orders of magnitude lower than for dry samples. Nonetheless, hybrids with GPTMS at the rupture strain point in wet state, preserved more or less their original morphology, while samples without crosslinker resulted dispersed in small pieces in the liquid after fracture. 


\subsection{In Vitro Bioactivity Experiments}

Figure 7 shows SEM micrographs of some hybrids exhibiting bioactivity. All of the samples displayed the precipitation of an apatite-like on the surfaces of the samples about 21 days after immersion in SBF in form of small spherulites. Physiochemical characterization of HAp was performed by using three different techniques: 1 . SEM, to observe the characteristic morphology of microcrystals; 2. Elemental EDS analysis, to determine $\mathrm{Ca} / \mathrm{P}$ compositional variations across the specimen surface; 3. FFT from HRTEM-SAED images, to confirm the crystalline nature of samples.
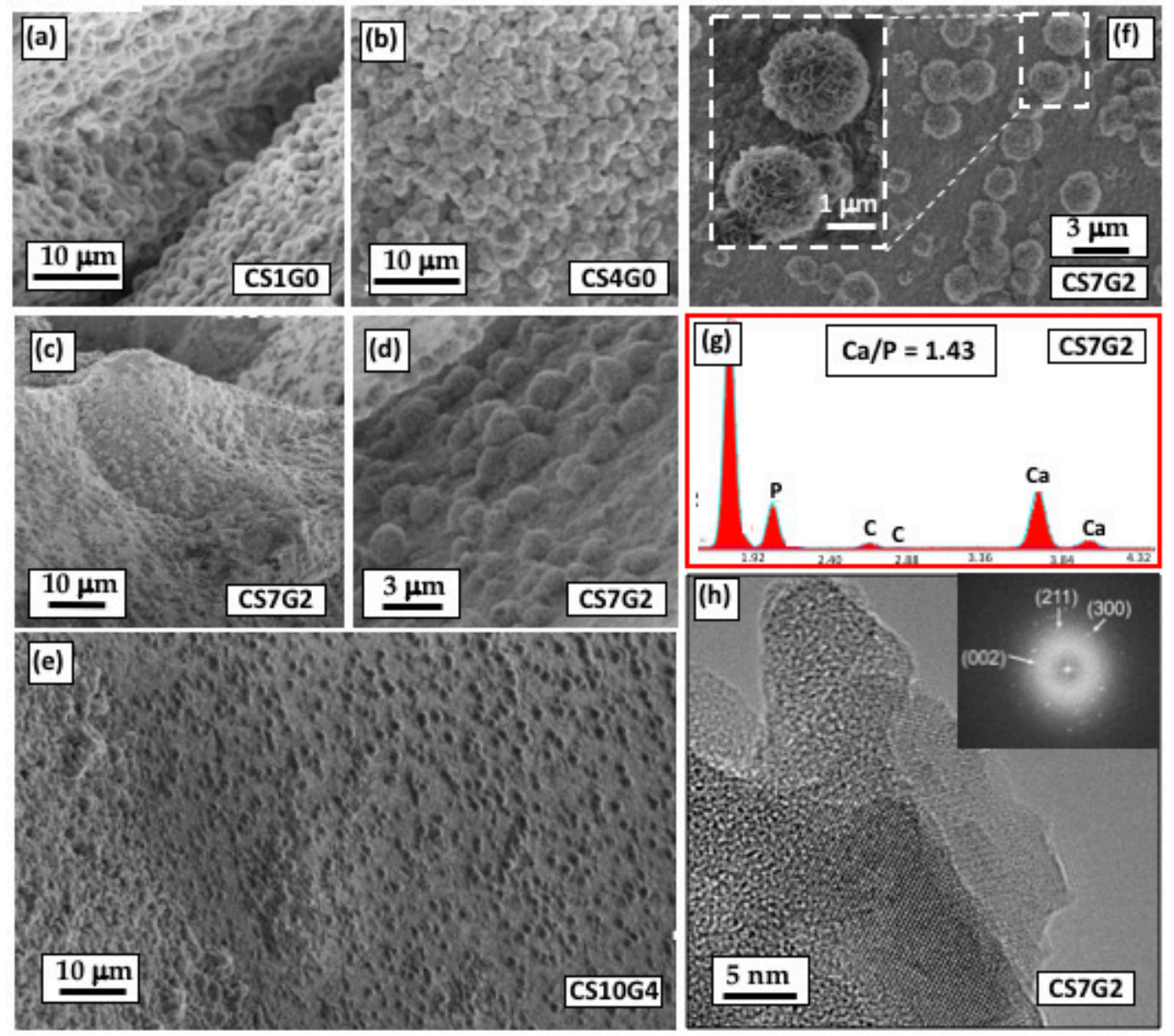

Figure 7. SEM micrographs of the apatite formed on the surfaces of the following hybrid aerogels soaked in SBF for 21 days: (a) CS1G0; (b) CS4G0; (c) CS7G2; (d) magnification of precedent micrograph for CS7G2; (e) CS10G4; (f) CS7G2; (g) EDS spectrum from CS7G2 from which Ca/P molar ratio 1.43 was found; (h) HRTEM micrograph of CS7G2 and corresponding SAED pattern (inset).

First, it was observed that spherulites started to precipitate on the aerogels about 7 days after the samples were soaked in SBF, becoming larger and more abundant with increasing soaking time. This mineral phase was formed through heterogeneous nucleation that take place at preferred nucleation sites on the surface of aerogels, forming a layer that recovered it more or less within 21 days soaking, as shown in the micrographs. Thus, Figure 7a,b show surfaces of hybrids CS1G0 and CS4G0 respectively, almost totally covered with HAp spherulites about $2 \mu \mathrm{m}$ size.

The presence of GPTMS in CS7G2 hybrid provided higher crosslinking density and a more compacted surface. Nonetheless, it also showed a good bioactive response, with HAp recovering all the irregularities of the surface area (Figure 7c), and growing from many surface nucleation sites, as detailed in Figure 7d. Furthermore, CS10G4 aerogel, showing the highest crosslinking density, behaved similarly to the CS7G2, but the surface density of precipitates was the lowest observed 
in all of the studied samples (Figure 7e), signifying a weak bioactive response in the same soaking time. Otherwise, CS7G2 also showed regions whose surface was not totally recovered by HAp spherulites. (Figure 7f). Higher-magnification micrograph of the HAP crystals formed on CS7G2 soaked in SBF for 21 days showed that the crystal morphology of spherulites consists of a large number of petal-like crystals with the typical cauliflower structure (inset Figure 7f). According to the EDS analysis performed on the CS7G2 sample, the growing mineral phase is calcium-deficient with a $\mathrm{Ca} / \mathrm{P}$ ratio of 1.43 (Figure $7 \mathrm{~g}$ ). This ratio is expected to increase by simply extending the soaking time to 1 month, desirably reaching values in the range 1.50-1.67 where most biological apatites are usually found.

TEM-EDX and selected area electron diffraction (SAED) pattern confirmed these results. Hence, HRTEM micrograph (Figure 7h) of CS7G2 sample revealed the existence of nanocrystals randomly distributed in the hybrid amorphous matrix, in the size range of about $10-15 \mathrm{~nm}$, probably formed in early stages of the biomineralization of biomimetic apatite. These observations suggest the existence of active surface sites $(\mathrm{Si}-\mathrm{OH})$ which promoted nucleation and growth of diverse calcium phosphates, mainly HAp. TEM-EDX microanalysis supported this hypothesis, giving $\mathrm{Ca} / \mathrm{P}$ ratios between 1.57 and 1.99 from different nanocrystals. Additionally, the small area electron diffraction (SAED) pattern from HRTEM image (inset of Figure $7 \mathrm{~h}$ ) shows bright spots according with the presence of calcium phosphate nanocrystals. In this sense, the d-space for (211), (300) and (002) planes were identified (e.g., d-space for (211) sample was $0.280 \mathrm{~nm}$, in good agreement with standard JCPDS (09-0432) files of HAP). From these observations, it can be concluded that the formed crystals are HAp particles in the precipitation and dissolution process of the apatite layer.

\subsection{Osteoblast Response In Vitro}

\subsubsection{Cell Morphology and Spreading}

Attachment, cell growth and phenotypic changes of osteoblasts grown in vitro appeared to be substantially better in cells grown on CS7G2 or CS10G4 samples than in cells grown on the bare substrata, and revealed a successful cell attachment with marked morphological changes, like filopodial and lamellipodial emission, and an improved cell spreading. When experimental groups were compared for the variable number of cells, significant differences were found at initial experimental times $(48,72 \mathrm{~h})$ between CS7G2 and control ( $p=0.007)$ and between CS7G2 and CS10G4 $\left(p=1.38 \times 10^{-5}\right)$, and also when cell counts at $48 \mathrm{~h}$ and $72 \mathrm{~h}$ counts $\left(p=2.57 \times 10^{-6}\right)$ or $48 \mathrm{~h}$ and 1 week counts were compared $\left(p=8.97 \times 10^{-4}\right)$. No significant differences in cell number were found after 1 week in culture when control and experimental groups were compared and, instead, significant differences were found in differentiation features related to cell migration and adhesion. Due to the presence of aerogels, osteoblasts developed filopodia and lamellipodia as markers of cell migration that are absent in non-coated groups. Furthermore significantly more efficient focal adhesion sites and stress fibers appeared in the experimental groups. Live/dead staining revealed that the majority of cells were in a viable state (green) at all time points, with only a few dead cells (red) as shown in Figure 8.

After $48 \mathrm{~h}$ in culture, cell spreading evolved to a near confluence stage, with well differentiated osteoblasts adhered to the surface and tethering contacts to the neighboring cells. Osteoblasts grown on bare glass, although well adhered, did not spread to confluence, showing discrete cell overlapping after $48 \mathrm{~h}$ in culture (Figures 9 and 10). From $72 \mathrm{~h}$ onwards, cells grown on experimental substrata elongated, and cytoskeletal polarization increased with a significant number of mature focal adhesions linked to actin stress fibers. After 1 week Cells grown on CS10G4 appeared to be more elongated than control and CS7G. 

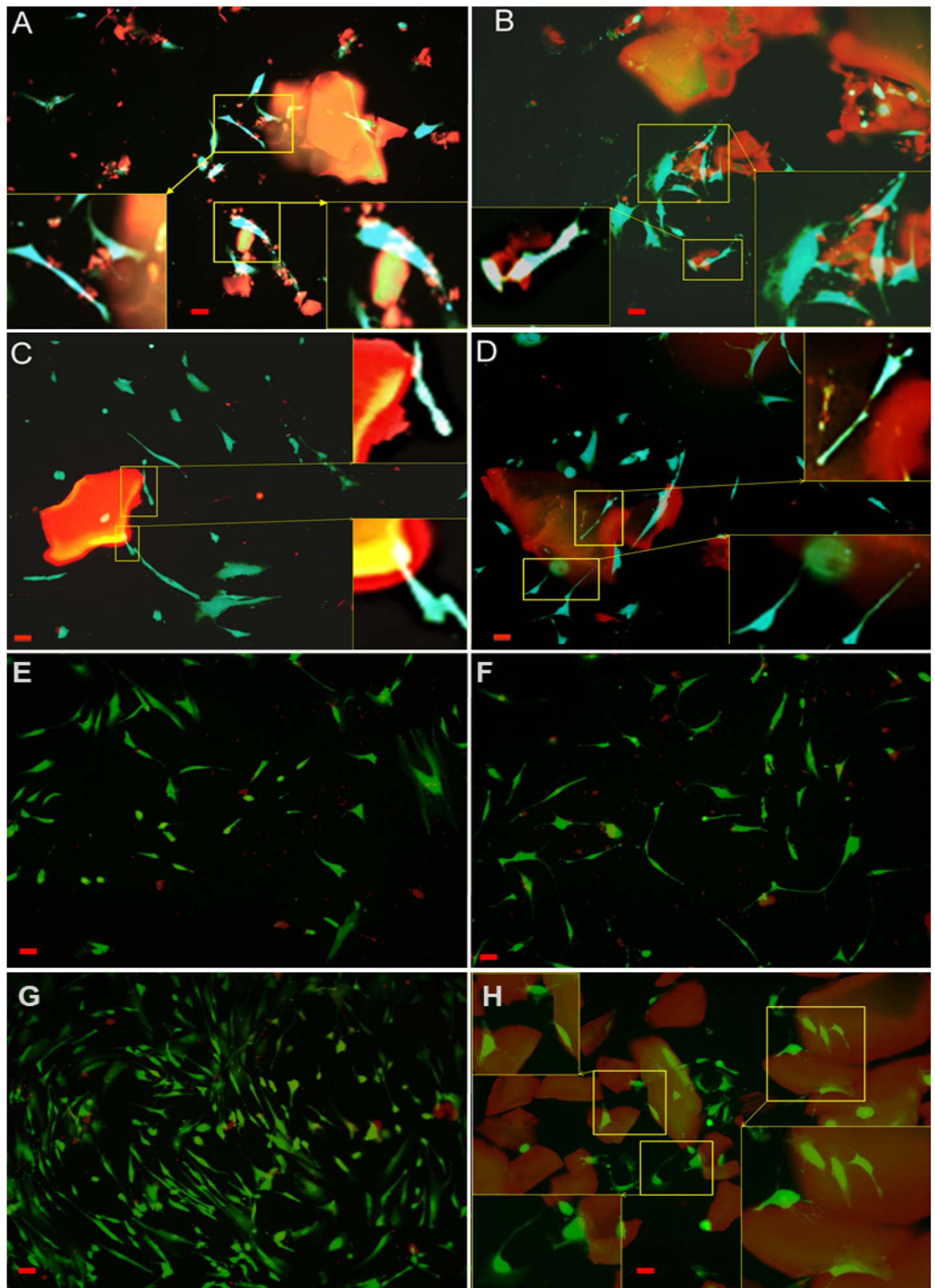

Figure 8. Live/Dead staining of osteoblasts growing on (A): CS4G0 after $48 \mathrm{~h}$ in culture; (B): CS4G0 after $72 \mathrm{~h}$ in culture; (C): CS7G2 after $48 \mathrm{H}$ in culture; (D): CS7G2 after $72 \mathrm{~h}$ in culture; (E): Control cells grown on glass after $48 \mathrm{~h}$ in culture; $(\mathbf{F})$ : Control cells grown on glass after $72 \mathrm{~h}$ in culture. In $(\mathrm{G})$ : Control cells grown on glass after 1 week in culture; $(\mathbf{H})$ : osteoblasts grown on CS10G4 after 1 week in culture. Live cells appear green; nuclei of dead cells fluoresce red once examined with fluorescence microscope (10x objective lens). Scale bar represents $50 \mu \mathrm{m}$. Squares select and amplify filopodial emissions pointing to material surface. 

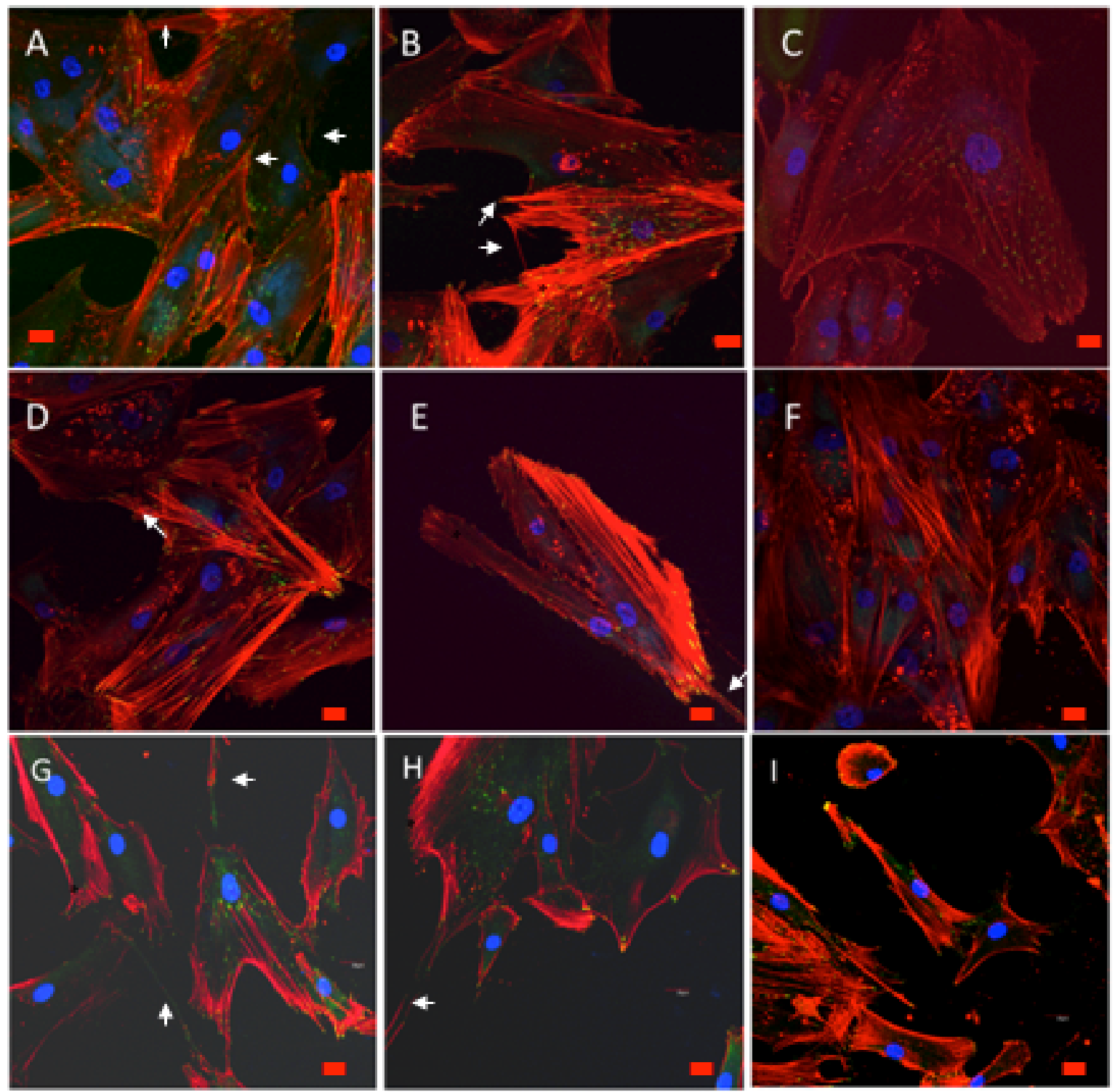

Figure 9. $\mathrm{HOB}^{\circledR}$ osteoblasts grown on CS7G2 sample after $48 \mathrm{~h}(\mathbf{A}, \mathbf{B}), 72 \mathrm{~h}(\mathbf{D}, \mathbf{E})$ and 1 week $(\mathbf{G}, \mathbf{H})$ in culture, and examined with confocal microscope (40x objective lens). Osteoblasts grown on glass were used as reference control, shown in (C), for $48 \mathrm{~h}$ in culture, (F) after $72 \mathrm{~h}$ in culture and (I) after 1 week. In red, rhodamine-phalloidin immunolabelled actin cytoskeletal fibers, showing polarization to material and actin cytoskeletal arrangement into stress fibers. Focal adhesions (yellow) were immunolabelled with antivinculin antibody. Nuclei (blue) were DAPI labelled. Arrow marks filopodial emissions, star marks lamellipodia. Scale bar represents $20 \mu \mathrm{m}$. 

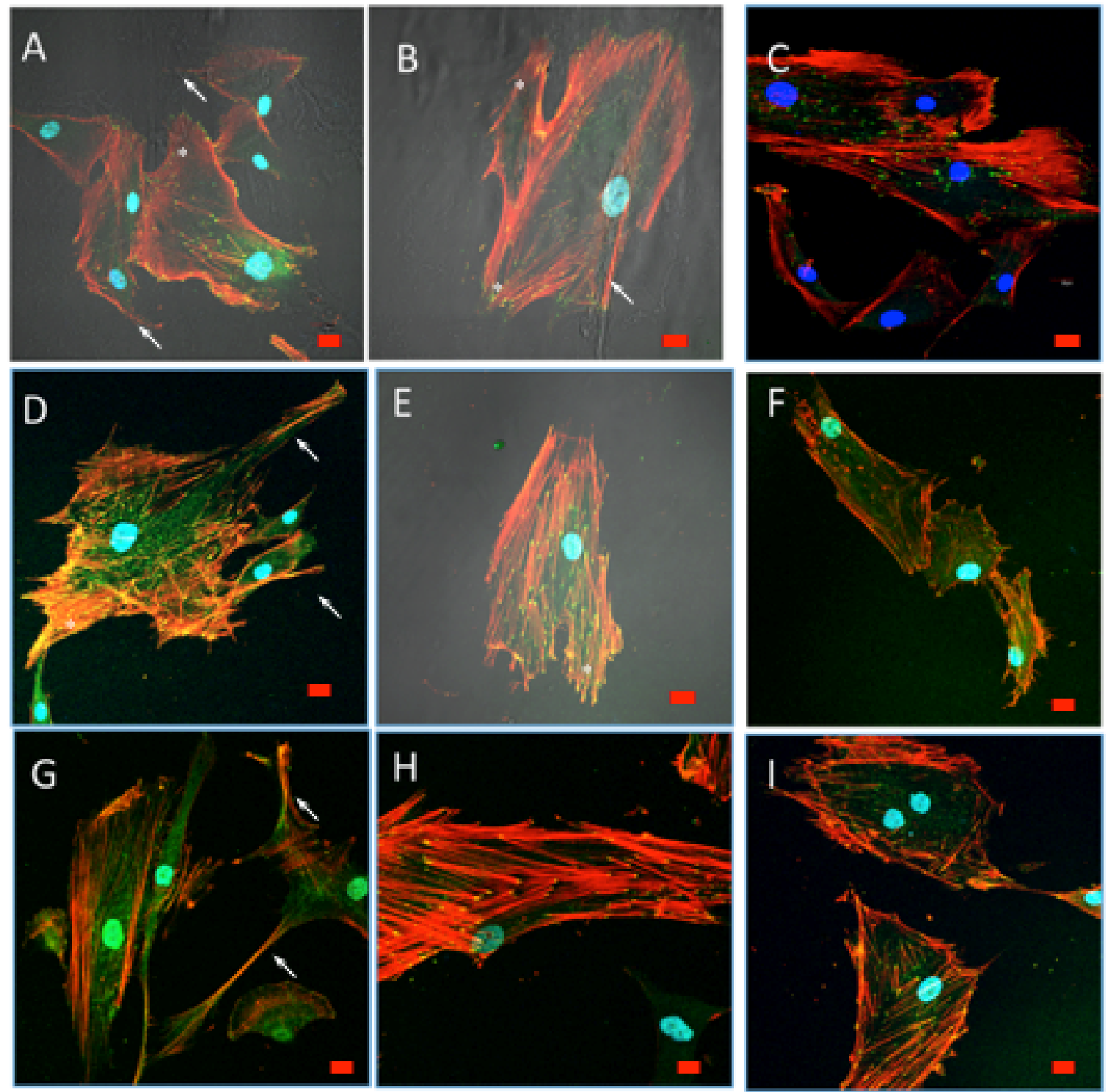

Figure 10. $\mathrm{HOB}^{\circledR}$ osteoblasts grown on CS10G4 sample after $48 \mathrm{~h}(\mathbf{A}, \mathbf{B}), 72 \mathrm{~h}(\mathbf{D}, \mathrm{E})$ and 1 week $(\mathbf{G}, \mathrm{H})$ in culture, and examined with confocal microscope (40× objective lens). Osteoblasts grown on glass were used as reference control, shown in (C), for $48 \mathrm{~h}$ in culture, (F) after $72 \mathrm{~h}$ in culture and (I) after 1 week. In red, rhodamine-phalloidin immunolabelled actin cytoskeletal fibers, showing polarization to material and actin cytoskeletal arrangement into stress fibers. Focal adhesions (yellow) were immunolabelled with antivinculin antibody. Nuclei (blue) were DAPI labelled. Arrow marks filopodial emissions, star marks lamellipodia. Scale bar represents $20 \mu \mathrm{m}$.

\subsubsection{Cytoskeletal Organization and Focal Adhesions}

Actin cytoskeleton immunolabelling of growing cells revealed clear differences both in cell behavior and in cytoskeletal arrangement. Osteoblasts grown on CS7G2 sample were phenotypically elongated and clustered in a reticular pattern from $48 \mathrm{~h}$ in culture onwards. From $48 \mathrm{~h}$ onwards osteoblasts elongated with increased elongation and stress fibers development, and a more defined osteoblast orientation was found, together with a higher number of well-developed focal adhesions. While cells grown on glass developed scarce or no stress fibers, cells grown on CS7G2 and CS10G4 samples showed a significant increase in well-developed stress fibers and focal adhesions $(p<0.05)$, mainly evident after 1 week $h$ in culture. Although both groups significantly differed from controls 
( $p=0.004$ and $p=0.014$, respectively) no significant differences were found between experimental groups along experimental times (Figures 9-11).
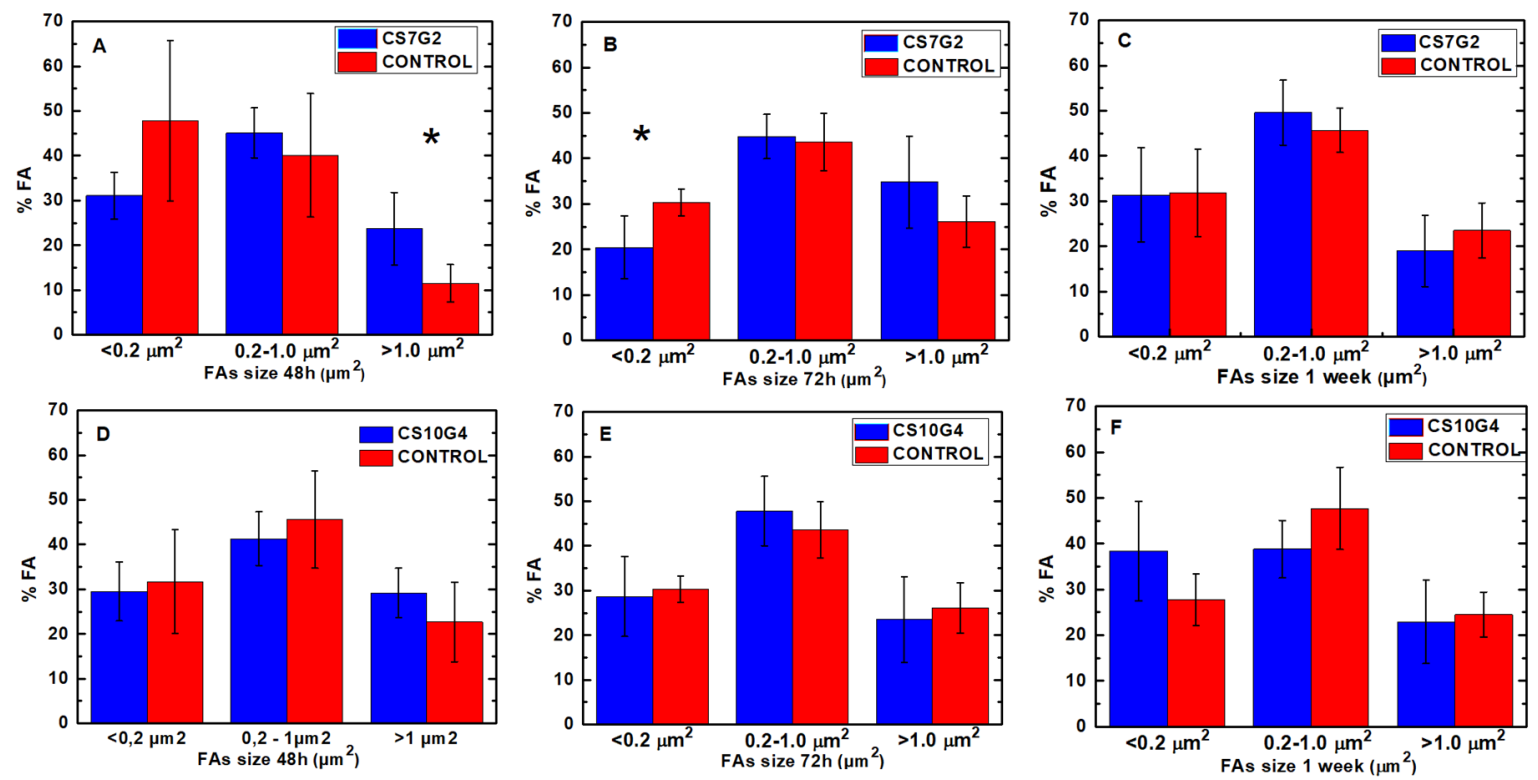

Figure 11. Percentage of FAs according to size. Comparative analysis between cells grown on CS7G2 and control groups at (A): 48 h hours in culture; (B): 72 h hours in culture; (C): 1 week in culture; and cells grown on CS10G4 and controls in (D): $48 \mathrm{~h}$ hours in culture; (E): $72 \mathrm{~h}$ hours in culture; (F): 1 week in culture $\left.{ }^{*}: p<0.005\right)$.

The focal adhesion complexes consists of integrin and actins vertically separated by a core that includes cytoskeletal elements such as vinculin [60-63]. As shown, mature focal adhesions appear in experimental groups, initially on the tips of filopodia and in the leading edge lamellipodia after $72 \mathrm{~h}$ (Figures 9-11). While in control cells a certain turnover can be appreciated, with small focal adhesions, in experimental groups the FA complexes maturated, together with a higher expression of stress fibers, as described by us and others $[60,62,64-66]$, as an expression of reduced cell migration and of the initial steps cell differentiation. After 1 week the percentage of mature and intermediate size FAs increased, together with a well-developed stress fiber network including a significant number of mature focal adhesions, mainly in cells grown on CS10G4 samples.

Spatiotemporal regulation of tension sustained at FAs has been described as essential for regulation of cell migration and settlement pointing to extracellular matrix remodeling and new bone formation. Force-mediated FA signaling together with actin bundles organization in stress fibers regulates cell proliferation and differentiation. Both CS7G2 and CS10G4 have demonstrated to be bioactive and non-cytotoxic and, at the same time, induce focal adhesion formation and maturation of $\mathrm{HOB}^{\circledR}$ cells in culture. In the presence of aerogels, osteoblasts change their morphology showing changes in cell morphology compatible with cell migration, such as filopodial and lamellipodial emissions towards material surface, at initial experimental times, reinforced with focal adhesion and stress fibers development.

According to our data, time dependent maturation of focal adhesion with significant presence of mature focal adhesion complexes and stress fiber development appears earlier in CS10G4 samples, while in cells grown in the presence of CS7G2 nascent and punctate focal adhesion points remaining for a longer period of time, located in periphery, thus indicating a sustained migration capability significantly higher than control cells and presumably induced by the biomaterial. This data are in agreement with the mechanical properties described above and, although the mechanical response in SBF is not as good as in dry conditions, the mechanoinductive properties of the biomaterial appear to be adequate. 
Taken together, these results point to a positive effect on $\mathrm{HOB}^{\circledR}$ cells of the proposed material in which both physicochemical and topographical properties appear to be involved [60,67-72].

\section{Conclusions}

CS-silica and CS-GPTMS-silica mesoporous hybrid aerogels with interconnected high porosity could be potentially used as substitute material for bone tissue regeneration. Monolith crack free specimens were obtained by sol-gel, followed by $\mathrm{CO}_{2}$ supercritical drying. The aerogels presented a fast uptake and swelling in PBS solution by fast imbibition, with swelling capacities ranging from 1.75 to 3.75 by decreasing the GPTMS content from 4 to 2 molar ratio with respect to CS monomer. Mechanical solicitation of class II hybrid crosslinked aerogels in swollen state in PBS, showed compressive strengths about $100-250 \mathrm{kPa}$, retaining their monolith geometry until fracture, thus exhibiting their potential efficacity to fill the empty space of bone defects. Further understanding of degradation kinetics to examine the time dependence of weight losses during soaking in PBS is required. Also the quantification of silicon release will be important to completely describe the hydrolytic degradation process of the hybrids, in order to perform this novel bioactive system for conducting hydrophilic therapeutic biomaterials to improve bone tissue engineering. Furthermore, the ability to induce and control the growth of a bioactive layer formed by HAp spherulites above $2 \mu \mathrm{m}$ in diameter after 21 days of soaking in SBF promotes the adhesion and proliferation of osteoblasts, contributing effectively in the bone regeneration process. Although the exact relationship between focal adhesion maturation and traction forces role is not yet elucidated, our results clearly indicate that CS-GPTMS-silica hybrids are not only biocompatible and bioactive, without cytotoxically effects, but also induce cell adhesion, cytoskeletal rearrangement and elongation with stress fibers development due to the presence of mature focal adhesion complexes. The results described point to the materials above as good alternatives in bone tissue cells recruitment and maturation, inducing an excellent initial osteoblast response in vitro.

Supplementary Materials: The following are available online at http://www.mdpi.com/2073-4360/12/11/2723/s1, Figure S1. Image of CS/GPTMS-SiO2 hybrid aerogel monoliths with different GPTMS content obtained by $\mathrm{CO}_{2}$ supercritical drying. Left (CS4G0), centre (CS7G2) and right (CS10G4) samples containing 10.3, 8.0 and 9.7 $w \mathrm{t} \%$ chitosan, respectively; Figure S2. (a) N2 physisorption isotherms of selected CS/GPTMS-SiO 2 aerogels with different GPTMS/CS molar ratio and (b) their corresponding pore size distributions (PSD); Figure S3. Thermogravimetry TG and differential thermogravimetry DTG (inset) for CS1G0, CS4G0, CS7G2 and CS10G4 hybrid aerogels; Figure S4. Stress-strain curves for selected samples (a) uniaxial compression of dry aerogels, as taken from the autoclave; (b) uniaxial compression of corresponding wet aerogel samples saturated in PBS solution (w samples).

Author Contributions: Conceptualization, M.V.R.-P. and M.P.; methodology, M.V.R.-P., A.P.-M., M.d.M.M.-D., M.S. and M.P.; formal analysis, M.V.R.-P., A.P.-M., M.S. and M.P.; investigation, M.V.R.-P., A.P.-M., D.M.d.-1.-S., M.d.M.M.-D., G.P.-T., J.I.V.-P., R.F.-M., M.S., N.d.1.R.-F. and M.P.; resources, D.M.d.-1.-S., J.I.V.-P., M.S., N.d.1.R.-F. and M.P.; data curation, M.V.R.-P., M.S., and M.P.; writing-original draft preparation, M.V.R.-P., M.S. and M.P.; writing-review and editing, M.S. and M.P.; supervision, M.S., N.d.l.R.-F. and M.P.; project administration, M.S.; funding acquisition, M.S. All authors have read and agreed to the published version of the manuscript.

Funding: This research was 80\% financially supported by Andalucía FEDER/ITI 2014-2020 Grant for PI 013/017 and Junta de Andalucía TEP115 and CTS 253 PAIDI research groups (Spain).

Acknowledgments: The authors would like to acknowledge J. VilchesTroya, retired Professor of Histology and Pathology of the University of Cadiz, for his expert advice and supervision. We thank also SEM, TEM, ICP and EA divisions of the Central Services of Science and Technology (SCCYT) of the University of Cadiz, for their technical help and support.

Conflicts of Interest: The authors declare no conflict of interest.

\section{References}

1. García-González, C.A.; Budtova, T.; Durães, L.; Erkey, C.; Del Gaudio, P.; Gurikov, P.; Koebel, M.; Liebner, F.; Neagu, M.; Smirnova, I. An opinion paper on aerogels for biomedical and environmental applications. Molecules 2019, 24, 1815. [CrossRef] 
2. Maleki, H.; Durães, L.; García-González, C.A.; del Gaudio, P.; Portugal, A.; Mahmoudi, M. Synthesis and biomedical applications of aerogels: Possibilities and challenges. Adv. Colloid Interface Sci. 2016, 236, 1-27. [CrossRef]

3. Zhao, S.; Malfait, W.J.; Guerrero-Alburquerque, N.; Koebel, M.M.; Nyström, G. Biopolymer Aerogels and Foams: Chemistry, Properties, and Applications. Angew. Chem. Int. Ed. 2018, 57, 7580-7608. [CrossRef]

4. Soorbaghi, F.P.; Isanejad, M.; Salatin, S.; Ghorbani, M.; Jafari, S.; Derakhshankhah, H. Bioaerogels: Synthesis approaches, cellular uptake, and the biomedical applications. Biomed. Pharmacother. 2019, 111, 964-975. [CrossRef]

5. Woh, K.K.; Yussof, R. Hybrid Green Aerogels: Processing and Morphology. In Biobased Aerogels: Polysaccharide and Protein-Based Materials; Thomas, S., Pothan, L.A., Mavelil-Sam, R., Eds.; Royal Society of Chemistry: London, UK, 2018; pp. 103-128, ISBN 978-1-78262-765-4.

6. Nita, L.E.; Ghilan, A.; Rusu, A.G.; Neamtu, I.; Chiriac, A.P. New Trends in Bio-Based Aerogels. Pharmaceutics 2020, 12, 449. [CrossRef]

7. Alhwaige, A.A.; Agag, T.; Ishida, H.; Qutubuddin, S. Biobased chitosan hybrid aerogels with superior adsorption: Role of graphene oxide in $\mathrm{C}_{\mathrm{O} 2}$ capture. RSC Adv. 2013, 3, 16011-16020. [CrossRef]

8. Hasan, M.; Gopakumar, D.A.; Arumughan, V.; Pottathara, Y.B.; Seantier, B.; Nzihou, A.; Thomas, S.; Rizal, S.; Hps, A.K. Robust Superhydrophobic Cellulose Nanofiber Aerogel for Multifunctional. Polymers 2019, 11, 495. [CrossRef]

9. Ulker, Z.; Erkey, C. An emerging platform for drug delivery: Aerogel based systems. J. Control. Release 2014, 177, 51-63. [CrossRef]

10. Govindarajan, D.; Duraipandy, N.; Srivatsan, K.V.; Lakra, R.; Korapatti, P.S.; Jayavel, R.; Kiran, M.S. Fabrication of Hybrid Collagen Aerogels Reinforced with Wheat Grass Bioactives as Instructive Scaffolds for Collagen Turnover and Angiogenesis for Wound Healing Applications. ACS Appl. Mater. Interfaces 2017, 9, 16939-16950. [CrossRef]

11. Mahony, O.; Tsigkou, O.; Ionescu, C.; Minelli, C.; Ling, L.; Hanly, R.; Smith, M.E.; Stevens, M.M.; Jones, J.R. Silica-gelatin hybrids with tailorable degradation and mechanical properties for tissue regeneration. Adv. Funct. Mater. 2010, 20, 3835-3845. [CrossRef]

12. Betz, M.; García-González, C.A.; Subrahmanyam, R.P.; Smirnova, I.; Kulozik, U. Preparation of novel whey protein-based aerogels as drug carriers for life science applications. J. Supercrit. Fluids 2012, 72, 111-119. [CrossRef]

13. Ganesan, K.; Budtova, T.; Ratke, L.; Gurikov, P.; Baudron, V.; Preibisch, I.; Niemeyer, P.; Smirnova, I.; Milow, B. Review on the production of polysaccharide aerogel particles. Materials (Basel) 2018, 11, 2144. [CrossRef]

14. Demilecamps, A.; Beauger, C.; Hildenbrand, C.; Rigacci, A.; Budtova, T. Cellulose-silica aerogels. Carbohydr. Polym. 2015, 122, 293-300. [CrossRef]

15. Ayers, M.R.; Hunt, A.J. Synthesis and properties of chitosan-silica hybrid aerogels. J. Non. Cryst. Solids 2001, 285, 123-127. [CrossRef]

16. Rudaz, C.; Courson, R.; Bonnet, L.; Calas-Etienne, S.; Sallee, H.; Budtova, T. Aeropectin: Fully Biomass-Based Mechanically Strong and Thermal Superinsulating Aerogel. Biomacromolecules 2014, 15, 2188-2195. [CrossRef]

17. Ge, J.; Li, M.; Zhang, Q.; Yang, C.Z.; Wooley, P.H.; Chen, X.; Yang, S.Y. Silica aerogel improves the

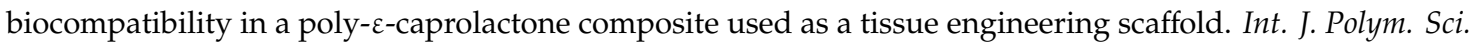
2013, 2013. [CrossRef]

18. Zargar, V.; Asghari, M.; Dashti, A. A Review on Chitin and Chitosan Polymers: Structure, Chemistry, Solubility, Derivatives, and Applications. ChemBioEng Rev. 2015, 2, 204-226. [CrossRef]

19. Rinaudo, M. Chitin and chitosan: Properties and applications. Prog. Polym. Sci. 2006, 31, 603-632. [CrossRef]

20. Rinki, K.; Dutta, P.K.; Hunt, A.J.; MacQuarrie, D.J.; Clark, J.H. Chitosan aerogels exhibiting high surface area for biomedical application: Preparation, characterization, and antibacterial study. Int. J. Polym. Mater. Polym. Biomater. 2011, 60, 988-999. [CrossRef]

21. Ji, J.; Wang, L.; Yu, H.; Chen, Y.; Zhao, Y.; Zhang, H.; Amer, W.A.; Sun, Y.; Huang, L.; Saleem, M. Chemical Modifications of Chitosan and Its Applications. Polym. Plast. Technol. Eng. 2014, 53, 1494-1505. [CrossRef]

22. Alves, N.M.; Mano, J.F. Chitosan derivatives obtained by chemical modifications for biomedical and environmental applications. Int. J. Biol. Macromol. 2008, 43, 401-414. [CrossRef] [PubMed]

23. Madera-Santana, T.J.; Herrera-Méndez, C.H.; Rodríguez-Núñez, J.R. An overview of the chemical modifications of chitosan and their advantages. Green Mater. 2018, 6, 131-142. [CrossRef] 
24. Sashiwa, H.; Aiba, S.I. Chemically modified chitin and chitosan as biomaterials. Prog. Polym. Sci. 2004, 29, 887-908. [CrossRef]

25. Trujillo, S.; Pérez-Román, E.; Kyritsis, A.; Gõmez Ribelles, J.L.; Pandis, C. Organic-inorganic bonding in chitosan-silica hybrid networks: Physical properties. J. Polym. Sci. Part B Polym. Phys. 2015, 53, 1391-1400. [CrossRef]

26. Götz, W.; Tobiasch, E.; Witzleben, S.; Schulze, M. Effects of silicon compounds on biomineralization, osteogenesis, and hard tissue formation. Pharmaceutics 2019, 11, 117. [CrossRef]

27. Takadama, H.; Kim, H.M.; Miyaji, F.; Kokubo, T.; Nakamura, T. Mechanism of apatite formation induced by silanol groups-TEM observation. J. Ceram. Soc. Jpn. 2000, 108, 118-121. [CrossRef]

28. Pipattanawarothai, A.; Suksai, C.; Srisook, K.; Trakulsujaritchok, T. Non-cytotoxic hybrid bioscaffolds of chitosan-silica: Sol-gel synthesis, characterization and proposed application. Carbohydr. Polym. 2017, 178, 190-199. [CrossRef]

29. Horvat, G.; Pantić, M.; Knez, Ž.; Novak, Z. Preparation and characterization of polysaccharide-silica hybrid aerogels. Sci. Rep. 2019, 9, 3-12. [CrossRef]

30. Shirosaki, Y.; Tsuru, K.; Moribayashi, H.; Hayakawa, S.; Nakamura, Y.; Gibson, I.R.; Osaka, A. Preparation of osteocompatible Si(IV)-enriched chitosan-silicate hybrids. J. Ceram. Soc. Jpn. 2010, 118, 989-992. [CrossRef]

31. Wang, J.; Zhou, Q.; Song, D.; Qi, B.; Zhang, Y.; Shao, Y.; Shao, Z. Chitosan-silica composite aerogels: Preparation, characterization and Congo red adsorption. J. Sol-Gel Sci. Technol. 2015, 76, 501-509. [CrossRef]

32. Wang, D.; Liu, W.; Feng, Q.; Dong, C.; Liu, Q.; Duan, L.; Huang, J.; Zhu, W.; Li, Z.; Xiong, J.; et al. Effect of inorganic/organic ratio and chemical coupling on the performance of porous silica/chitosan hybrid scaffolds. Mater. Sci. Eng. C 2017, 70, 969-975. [CrossRef] [PubMed]

33. Błaszczyński, T.; Ślosarczyk, A.; Morawski, M. Synthesis of silica aerogel by supercritical drying method. Procedia Eng. 2013, 57, 200-206. [CrossRef]

34. Chang, X.; Chen, D.; Jiap, X. Chitosan-based aerogels with high adsorption performance. J. Phys. Chem. B 2008, 112, 7721-7725. [CrossRef]

35. Zhao, S.; Malfait, W.J.; Jeong, E.; Fischer, B.; Zhang, Y.; Xu, H.; Angelica, E.; Risen, W.M.; Suggs, J.W.; Koebel, M.M. Facile One-Pot Synthesis of Mechanically Robust Biopolymer-Silica Nanocomposite Aerogel by Cogelation of Silicic Acid with Chitosan in Aqueous Media. ACS Sustain. Chem. Eng. 2016, 4, 5674-5683. [CrossRef]

36. Stergar, J. Review of aerogel-based materials in biomedical applications. J. Sol-Gel Sci. Technol. 2016, 77, 738-752. [CrossRef]

37. Pandis, C.; Madeira, S.; Matos, J.; Kyritsis, A.; Mano, J.F.; Ribelles, J.L.G. Chitosan-silica hybrid porous membranes. Mater. Sci. Eng. C 2014, 42, 553-561. [CrossRef]

38. Guillory, X.; Tessier, A.; Gratien, G.O.; Weiss, P.; Colliec-Jouault, S.; Dubreuil, D.; Lebreton, J.; Le Bideau, J. Glycidyl alkoxysilane reactivities towards simple nucleophiles in organic media for improved molecular structure definition in hybrid materials. RSC Adv. 2016, 6, 74087-74099. [CrossRef]

39. Gómez-Romero, P.; Sanchez, C. Hybrid Materials, Functional Applications. An Introduction. In Functional Hybrid Materials; Gómez-Romero, P., Sanchez, C., Eds.; Wiley-VCH: Hoboken, NJ, USA, 2005; pp. 1-14, ISBN 3527304843.

40. Connell, L.S.; Romer, F.; Suárez, M.; Valliant, E.M.; Zhang, Z.; Lee, P.D.; Smith, M.E.; Hanna, J.V.; Jones, J.R. Chemical characterisation and fabrication of chitosan-silica hybrid scaffolds with 3-glycidoxypropyl trimethoxysilane. J. Mater. Chem. B 2014, 2, 668-680. [CrossRef]

41. Wang, D.; Romer, F.; Connell, L.; Walter, C.; Saiz, E.; Yue, S.; Lee, P.D.; McPhail, D.S.; Hanna, J.V.; Jones, J.R. Highly flexible silica/chitosan hybrid scaffolds with oriented pores for tissue regeneration. J. Mater. Chem. B 2015, 3, 7560-7576. [CrossRef]

42. García-González, C.A.; Alnaief, M.; Smirnova, I. Polysaccharide-based aerogels-Promising biodegradable carriers for drug delivery systems. Carbohydr. Polym. 2011, 86, 1425-1438. [CrossRef]

43. Van Vlierberghen, S.; Graulus, G.-J.; Samal, S.K.; Nieuwenhove, I.; Dubruel, P. Porous hydrogel biomedical foam scaffolds for tissue repair. In Biomedical Foams for Tissue Engineering Applications; Netti, P.A., Ed.; Woodhead Publishing: London, UK, 2014; pp. 335-390, ISBN 9780857098047.

44. Follmann, H.D.M.; Oliveira, O.N.; Lazarin-Bidóia, D.; Nakamura, C.V.; Huang, X.; Asefa, T.; Silva, R. Multifunctional hybrid aerogels: Hyperbranched polymer-trapped mesoporous silica nanoparticles for sustained and prolonged drug release. Nanoscale 2018, 10, 1704-1715. [CrossRef] 
45. Liu, Y.L.; Su, Y.H.; Lai, J.Y. In situ crosslinking of chitosan and formation of chitosan-silica hybrid membranes with using $\gamma$-glycidoxypropyltrimethoxysilane as a crosslinking agent. Polymer (Guildf) 2004, 45, 6831-6837. [CrossRef]

46. Park, S.B.; You, J.O.; Park, H.Y.; Haam, S.J.; Kim, W.S. A novel pH-sensitive membrane from chitosanTEOS IPN; preparation and its drug permeation characteristics. Biomaterials 2001, 22, 323-330. [CrossRef]

47. Saguy, I.S.; Marabi, A.; Wallach, R. Liquid imbibition during rehydration of dry porous foods. Innov. Food Sci. Emerg. Technol. 2005, 6, 37-43. [CrossRef]

48. Kokubo, T.; Takadama, H. How useful is SBF in predicting in vivo bone bioactivity? Biomaterials 2006, 27, 2907-2915. [CrossRef] [PubMed]

49. Esquivias, L.; Pinero, M.; Morales-Florez, V.; Rosa-Fox, N. Aerogels Synthesis by Sonocatalysis: Sonogels. In Aerogels Handbook; Aegerter, M.A., Leventis, N., Koebel, M.M., Eds.; Springer Link: New York, NY, USA, 2011; pp. 419-445, ISBN 9781441975898.

50. Thommes, M.; Kaneko, K.; Neimark, A.V.; Olivier, J.P.; Rodriguez-Reinoso, F.; Rouquerol, J.; Sing, K.S.W. Physisorption of gases, with special reference to the evaluation of surface area and pore size distribution. Pure Appl. Chem. 2015, 87, 1052. [CrossRef]

51. Morales-Florez, V.; Piñero, M.; Braza, V.; del Mar Mesa, M.; Esquivias, L.; de la Rosa-Fox, N. Absorption capacity, kinetics and mechanical behaviour in dry and wet states of hydrophobic DEDMS/TEOS-based silica aerogels. J. Sol-Gel Sci. Technol. 2017, 81. [CrossRef]

52. Azhary, S.Y.; Purnama, D.; Florena, F.F.; Vanitha, M.; Panatarani, C.; Joni, I.M. Synthesis and characterization of chitosan: $\mathrm{SiO}_{2}$ nanocomposite by ultrasonic spray drying Synthesis and characterization of chitosan: $\mathrm{SiO}_{2}$ nanocomposite by ultrasonic spray drying. Mater. Sci. Eng. 2019, 550, 6. [CrossRef]

53. Al-Oweini, R.; El-Rassy, H. Synthesis and characterization by FTIR spectroscopy of silica aerogels prepared using several $\mathrm{Si}(\mathrm{OR}) 4$ and $\mathrm{R}^{\prime \prime} \mathrm{Si}\left(\mathrm{OR}^{\prime}\right) 3$ precursors. J. Mol. Struct. 2009, 919, 140-145. [CrossRef]

54. Budnyak, T.M.; Pylypchuk, I.V.; Tertykh, V.A.; Yanovska, E.S.; Kolodynska, D. Synthesis and adsorption properties of chitosan-silica nanocomposite prepared by sol-gel method. Nanoscale Res. Lett. 2015, 10, 87-96. [CrossRef]

55. Lim, S.; Hudson, S.M. Synthesis and antimicrobial activity of a water-soluble chitosan derivative with a fiber-reactive group. Carbohydr. Res. 2004, 339, 313-319. [CrossRef] [PubMed]

56. Kumirska, J.; Kaczy, Z.; Bychowska, A. Application of Spectroscopic Methods for Structural Analysis of Chitin and Chitosan. Mar. Drugs 2010, 8, 1567-1636. [CrossRef] [PubMed]

57. Li, C.P.; Weng, M.C.; Huang, S.L. Preparation and Characterization of pH Sensitive Chitosan/3Glycidyloxypropyl Trimethoxysilane (GPTMS) Hydrogels by Sol—Gel Method. Polymers 2020, 12, 1326. [CrossRef] [PubMed]

58. Zhou, Y. Engineering of Aerogel-Based Biomaterials for Biomedical Applications. Int. J. Nanomed. 2020, 15, 2363-2378.

59. Taylor, P.; Lai, S.; Yang, A.J.; Chen, W.; Hsiao, J.; Lai, S. Polymer-Plastics Technology and Engineering the Properties and Preparation of Chitosan/Silica Hybrids Using Sol-Gel Process the Properties and Preparation of Chitosan/Silica Hybrids Using Sol-Gel Process. Polym. Plast. Technol. Eng. 2006, 45, 37-41. [CrossRef]

60. Coyer, S.R.; Singh, A.; Dumbauld, D.W.; Calderwood, D.A.; Craig, S.W.; Delamarche, E.; García, A.J. Nanopatterning reveals an ECM area threshold for focal adhesion assembly and force transmission that is regulated by integrin activation and cytoskeleton tension. J. Cell Sci. 2012, 125, 5110-5123. [CrossRef]

61. Ciobanasu, C.; Faivre, B.; Le Clainche, C. Integrating actin dynamics, mechanotransduction and integrin activation: The multiple functions of actin binding proteins in focal adhesions. Eur. J. Cell Biol. 2013, 92, 339-348. [CrossRef]

62. McNamara, L.E.; Sjöström, T.; Burgess, K.E.V.; Kim, J.J.W.; Liu, E.; Gordonov, S.; Moghe, P.V.; Meek, R.M.D.; Oreffo, R.O.C.; Su, B.; et al. Skeletal stem cell physiology on functionally distinct titania nanotopographies. Biomaterials 2011, 32, 7403-7410. [CrossRef]

63. Mullen, C.A.; Vaughan, T.J.; Voisin, M.C.; Brennan, M.A.; Layrolle, P.; McNamara, L.M. Cell morphology and focal adhesion location alters internal cell stress. J. R. Soc. Interface 2014, 11. [CrossRef]

64. Terriza, A.; Díaz-Cuenca, A.; Yubero, F.; Barranco, A.; González-Elipe, A.R.; Caballero, J.L.G.; Vilches, J.; Salido, M. Light induced hydrophilicity and osteoblast adhesion promotion on amorphous TiO2. J. Biomed. Mater. Res. Part A 2013, 101A, 1026-1035. [CrossRef] 
65. Lamers, E.; van Horssen, R.; te Riet, J.; van Delft, F.C.M.J.M.; Luttge, R.; Walboomers, X.F.; Jansen, J.A. The influence of nanoscale topographical cues on initial osteoblast morphology and migration. Eur. Cells Mater. 2010, 20, 329-343. [CrossRef] [PubMed]

66. Matschegewski, C.; Birkholz, H.; Staehlke, S.; Loeffler, R.; Kern, D.P.; Engel, K.; Nebe, J.B. Quantitative analysis of the cellular actin cytoskeleton on geometrically designed surface topography. Mater. Sci. Forum 2012, 706-709, 543-548. [CrossRef]

67. Sanz-Herrera, J.A.; García-Aznar, J.M.; Doblaré, M. On scaffold designing for bone regeneration: A computational multiscale approach. Acta Biomater. 2009, 5, 219-229. [CrossRef] [PubMed]

68. Zinger, O.; Anselme, K.; Denzer, A.; Habersetzer, P.; Wieland, M.; Jeanfils, J.; Hardouin, P.; Landolt, D. Time-dependent morphology and adhesion of osteoblastic cells on titanium model surfaces featuring scale-resolved topography. Biomaterials 2004, 25, 2695-2711. [CrossRef] [PubMed]

69. Maggi, A.; Li, H.; Greer, J.R. Three-dimensional nano-architected scaffolds with tunable stiffness for efficient bone tissue growth. Acta Biomater. 2017, 63, 294-305. [CrossRef]

70. Geiger, B.; Spatz, J.P.; Bershadsky, A.D. Environmental sensing through focal adhesions. Nat. Rev. Mol. Cell Biol. 2009, 10, 21-33. [CrossRef]

71. Parsons, J.T.; Horwitz, A.R.; Schwartz, M.A. Cell adhesion: Integrating cytoskeletal dynamics and cellular tension. Nat. Publ. Gr. 2010, 11, 633-643. [CrossRef]

72. Gardel, M.L.; Schneider, I.C.; Aratyn-schaus, Y.; Waterman, C.M. Mechanical Integration of Actin and Adhesion Dynamics in Cell Migration. Annu. Rev. Cell Dev. Biol. 2010, 26, 315-335. [CrossRef]

Publisher's Note: MDPI stays neutral with regard to jurisdictional claims in published maps and institutional affiliations.

(C) 2020 by the authors. Licensee MDPI, Basel, Switzerland. This article is an open access article distributed under the terms and conditions of the Creative Commons Attribution (CC BY) license (http://creativecommons.org/licenses/by/4.0/). 